\title{
AVALIAÇÃO DO POTENCIAL BIOLÓGICO DE Lutzomyia intermedia s.L. COMO VETOR DA LEISHMANIOSE TEGUMENTAR AMERICANA NA ZONA RURAL DO MUNICÍPIO DE CONCHAL, ESTADO DE SÃO PAULO
}

\section{Cláudio Casanova}

Tese de Doutorado apresentada ao Departamento de Epidemiologia da Faculdade de Saúde Pública da Universidade de São Paulo para obtenção do Grau de Doutor.

Área de concentração: Epidemiologia

Orientador: Prof. Dr. Delsio Natal

São Paulo 2001

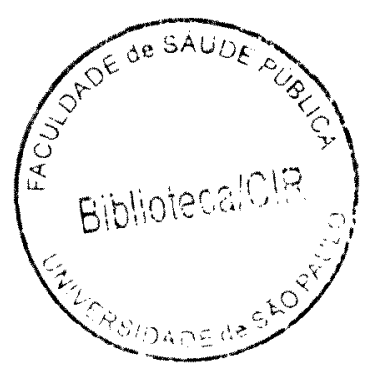


Autorizo, exclusivamente para fins acadêmicos e científicos, a reprodução total ou parcial desta tese, por processos fotocopiadores.

Assinatura:

Data:

$41768 / 2002$ doe 
À minha querida mãe.

Ao meu querido pai (em memória). 


\section{AGRADECIMENTOS}

Ao Prof. Dr. Delsio Natal pelo companheirismo e pela orientação.

Aos Profs. Flávio A.M. dos Santos e Ademir Petenati pela orientação na parte estatística.

Aos Profs. Eunice A. B. Galati e Angelo P. do Prado pelas sugestões dadas por ocasiào do exame de qualificação.

À Roseli La Corte dos Santos pelas discussões e pela leitura do manuscrito.

Ao João Giudice pelo fornecimento dos mapas e dados meteorológicos.

À Companhia Energética de São Paulo e Companhia de Geração Elétrica Tietê pelo apoio logístico.

Ao CNPq pela concessão da bolsa de estudos.

À SUCEN pela oportunidade oferecida.

Ao amigo Antonio Ismael Paulino da Costa pelo incentivo e pelas discussões.

Ao Norberto (SUCEN- Presidente Prudente) pela ajuda na triagem do material e identificação dos flebotomíneos.

À estagiária Cláudia Renata Siqueira pela ajuda na montagem do banco de dados.

Aos colegas da SUCEN, Delvo Baitelo e Clemison N. Mattos pela ajuda na confecção e montagem das armadilhas no campo, e Wanda de Carvalho pelo auxílio e paciência na eterna arrumação do depósito de material de campo.

Aos colegas da SUCEN, Marcão, Jamil, Rosemir e Osmar pela ajuda nas coletas de campo. 
Aos motoristas Milton e Roberto (CESP) e Barbosa (Geração Tietê) pela dedicação e garantia de chegada

Às colegas da biblioteca da FSP/USP pela atenção a este humilde usuário.

Aos colegas da SUCEN e da Pós-graduação pela amizade e companheirismo.

À Maricy pelo carinho, incentivo e apoio e pela compreensão e enorme paciência. 


\section{RESUMO}

Casanova, C. Avaliação do potencial biológico de Lutzomyia intermedia s.l. como vetor da leishmaniose tegumentar americana na zona rural do município de Conchal, Estado de São Paulo. São Paulo, 2001. [Tese de Doutorado - Faculdade de Saude Pública da USP].

Objetivo. Avaliar o potencial de Lutzomyia intermedia s. $l$. atuar como vetor da leishmaniose tegumentar americana, por meio de estimativas de parâmetros ecológicos e de capacidade vetorial tais como, dispersão ambiental, sobrevivência, tamanho populacional absoluto, duração do ciclo gonotrófico e comportamento alimentar, de populações da zona rural do município de Conchal.

Material e Métodos. Os estudos foram realizados em área de mata ciliar residual do rio Mogi Guaçu. A distribuição mensal e sazonal de $L$. intermedia s.l. foi caracterizada por meio de coletas noturnas sistemáticas. As estimativas da sobrevivência diária, tamanho absoluto, duração do ciclo gonotrófico e dispersão foram realizadas com o uso da técnica de marcação-soltura-recaptura. A taxa de sobrevivência diária foi estimada pela regressão linear do número de indivíduos recapturados e os dias corridos de coleta. $\mathrm{O}$ tamanho absoluto da população foi calculado pelo Índice de Lincoln, ajustado para taxas baixas de recaptura e incorporando a taxa de sobrevivência diária na estimativa. O comportamento alimentar das fêmeas de L. intermedia s.l. foi identificado com o uso de armadilhas tipo 
Disney, sem isca ou iscadas com cão, gambá e roedor, e pelo reconhecimento do sangue ingerido, com o uso da técnica de reação de precipitação.

Resultados. L. intermedia s.l. representou $99,4 \%$ dos flebotomíneos coletados e esteve presente em todos os meses e em todos os ambientes pesquisados. A média aritmética de dispersão foi de $53 \mathrm{~m}$ para os machos e de $55 \mathrm{~m}$ para as fềmeas, com cerca de $90 \%$ dos indíviduos, coletados a menos de $70 \mathrm{~m}$ do ponto de soltura. O tempo mediano de duração do ciclo gonotrófico foi de 3 dias. L. intermedia s.l. apresentou um comportamento alimentar oportunista, tanto em relação às iscas animais oferecidas, como em relação às fontes de alimentação disponíveis. A taxa de sobrevivência diária foi de $67,5 \%$ e a população absoluta de fềmeas variou entre 2.462 a 20.637 indivíduos.

Conclusões. A predominância quase que absoluta de $L$. intermedia s.l. em todos os meses do ano e em todos ambientes pesquisados, incluindo o peridomiciliar, sugere que esta espécie atue como principal vetor da leishmaniose tegumentar na zona rural do município de Conchal. Embora, L. intermedia s.l. não atravesse grandes distâncias, a dispersão de fềmeas para o ambiente peridomociliar, a partir da mata, indica que essa possa ser uma das possíveis vias de origem da infecção humana domiciliar. O comportamento alimentar oportunista, a alta frequência de alimentação e a alta abundância populacional alcançada em alguns meses conferem potencial biológico para $L$. intermedia $s . l$. atuar como vetor da leishmaniose tegumentar americana na região de estudo. No entanto, a baixa expectativa de vida. sugere que este potencial seja baixo.

Descritores: Lutzomyia intermedia s.l., marcação-soltura-recaptura, dispersão, sobrevivència, leishmaniose tegumentar americana. 


\section{SUMMMARY}

Casanova, C. Evaluation of the biological potential of Lutzomyia intermedia s.l. as a vector of american cutaneous leishmaniasis in a rural zone of the Conchal municipality, State of São Paulo. São Paulo, 2001 [PhD thesis - Faculty of Public Health, University of São Paulo].

Objectives. To evaluate the potential of Lutzomyia intermedia s.l. to act as a vector of american cutaneous leishmaniasis through estimations of ecological parameters and vectorial capacity such as environmental dispersal, survival, absolute size, duration of the gonotrophic cycle and feeding behaviour, in populations of the rural zone of the Conchal municipality.

Materials and methods. The study took place in a remnant of riparian forest adjacent to the Mogi Guaçu River. The monthly and seasonal distribution of L. intermedia s.l. was characterised by systematic nightly collections. Estimations of daily survival, absolute size and the duration of the gonotrophic and dispersal cycles were carried out using the mark-release-recapture technique. The rate of daily survival was estimated by linear regression of the number of individuals recaptured during consecutive days of collection. The absolute size of the population was calculated using the Index of Lincoln, adjusted for low rates of recapture, and incorporating the estimated daily rate of survival. The feeding behaviour of $L$. intermedia s.l. females was investigated using Disney traps baited 
with dogs, opossums and rodents, and through the identification of ingested blood using the technique of precipitation reactions.

Results. L. intermedia s.l. represented $99.4 \%$ of the sand flies collected and was present in all the months and habitats studied. The arithmetic mean of dispersal was $53 \mathrm{~m}$ for the males and $55 \mathrm{~m}$ for the females, with approximately $90 \%$ of individuals recaptured less than $70 \mathrm{~m}$ from the point of release. The average duration of the gonotrophic cycle was 3 days. L. intermedia s.l. showed opportunistic feeding behaviour, both in relation to the animal baits and the sources of feeding. The rate of daily survival was $67.5 \%$ and the absolute population of fernales varied between 2,464 and 20,637 .

Conclusions. The predominance of $L$. intermedia s.l. throughout the year and in all the habitats studied, including human settlements, suggests that it is a species that acts as the principal vector of cutaneous leishmaniasis in rural zones of the Conchal municipality. Although $L$ intermedia does not travel large distances, the dispersal of females from the forest to the peridomicile environment, indicates that this may be the origin of infections in human settlements. The opportunistic feeding behaviour, the high frequency of feeding and the high abundance of populations attained in some months, conveys the biological potential for L. intermedia s.l. to act as a vector of american cutaneous leishmaniasis in the study region. However, the low life expectation suggests that this potential is probably low.

Key words. Lutzomyia intermedia s.l., mark-release-recapture, dispersal, survival, american cutaneous leishmaniasis. 


\section{ÍNDICE}

1. INTRODUÇÃO 1

1.1. A leishmaniose tegumentar americana - LTA 1

1.2. Parâmetros ecológicos para a transmissão da LTA 5

2. OBJETIVOS 11

2.1. Objetivo Geral 11

2.2. Objetivos Específicos 11

3. MATERIAL E MÉTODOS 12

3.1. Área de estudo 12

3.2. Periodo de estudo 15

3.3. Dados meteorológicos 15

3.4. Coletas de flebotomíneos adultos 15

3.5. Distribuição espacial e temporal 16

3.6. Dispersão e parâmetros populacionais 17

3.6.1. Técnica de marcação-soltura-recaptura $\quad 18$

3.6.1.1. Avaliação do efeito do pó fluorescente na sobrevivência dos flebotomíneos $\quad 20$

3.6.2. Estimativas de dispersão 21

$\begin{array}{ll}\text { 3.6.3. Estimativas da sobrevivência diária } & 22\end{array}$

3.6.4. Estimativas do tamanho populacional, taxa de adição

$\begin{array}{ll}\text { e taxa de perda } & 23\end{array}$

3.7. Ciclo gonotrófico 24

3.8. Comportamento Alimentar 25

3.8.1 Preferência Alimentar 25

3.8.2. Hábito Alimentar 26

4. RESULTADOS 29

4.1. Flebotomíneos da área de estudo 29 
4.2. Distribuição mensal e espacial de L. intermedia s.l. 30

4.3. Dispersão ambiental e parâmetros populacionais 34

4.3.1. Teste laboratorial de sobrevivência 34

4.3.2. Sucesso de recaptura 36

4.3.3. Dispersão ambiental 37

4.3.4. Sobrevivência $\quad 42$

4.3.5. Tamanho da população e taxas de adição, perda e mudança $\quad 48$

4.3.6. Ciclo gonotrófico 51

4.4. Comportamento alimentar $\quad 52$

4.4.1. Preferência alimentar $\quad 52$

4.4.2. Hábito alimentar 55

5. DISCUSSÃO

6. CONCLUSÕES

7. REFERÊNCIAS BIBLIOGRÁFICAS 


\section{INTRODUÇÃO}

\subsection{A leishmaniose tegumentar americana - LTA}

As leishmanioses encontram-se entre as seis doenças infecto-parasitárias de maior importância mundial. Estima-se que cerca de 350 milhões de pessoas estariam expostas ao risco de aquisição de leishmaniose e que aproximadamente 12 milhões estariam infectadas (WHO 1990).

Dentre as leishmanioses que ocorrem no Brasil, a leishmaniose tegumentar americana - LTA está amplamente distribuída pelo território e apresenta uma notificação anual aproximada de 20.000 casos desde 1984 (KATZ 1997).

No Estado de São Paulo, no período de 1986 a 1995, aproximadamente 3.700 casos autóctones de LTA foram notificados (KATZ 1997). Até meados do século passado, a LTA apresentava-se no Planalto Paulista como uma verdadeira moléstia profissional, atingindo principalmente homens adultos que exerciam atividades relacionadas com as florestas (PESSÔA e MARTINS 1974). A partir da década de 70, a ocorrência de casos esporádicos, distribuidos por todas as faixas etárias e em ambos os sexos, caracterizam uma nova feição epidemiológica da doença no Estado (GOMES 1992; TOLEZANO 1994). A transmissão parece ocorrer principalmente no ambiente domiciliar, em áreas rurais com presença de matas residuais bastante alteradas (FORATTINI e col. 1976; TOLEZANO e col. 1980; GOMES e col. 1980; $1983 ; 1986 ; 1989)$.

Atualmente, no Estado de São Paulo, excluindo-se a floresta atlântica de encosta, que forma uma faixa quase contínua sobre a Serra do Mar, as áreas florestadas estão representadas por remanescentes de matas de planalto e ciliar. Estas 
são comumente encontradas ao longo dos rios do interior, pertencentes às bacias hidrográficas dos rios Grande, Paraná e Paranapanema (GIBBS e LEITÃO FILHO 1978).

No período de 1986 a 1995, os municípios situados na região do Vale do rio Mogi Guaçu, pertencente ao sistema hidrográfico do rio Grande, notificaram cerca úe 450 casos autóctones de LTA, acometendo principalmente pessoas que vivem próximas às matas ciliares deste rio e seus afluentes (MASCARINI e col. 1995). Esta região, quando comparada a outras do Estado, registrou no período de 1986 a 1992 o maior aumento do coeficiente de incidência da doença (TOLEZANO 1994). Mesmo assim, a região pode ser considerada como de baixa endemicidade, com ocorrência de casos esporádicos ou micro-surtos, distribuidos de forma não homogênea por todos seus municípios (MASCARINI e col. 1995, KATZ 1997).

A LTA é considerada essencialmente uma zoonose de ambiente florestal primitivo, que afeta animais silvestres, podendo o homem ser envolvido, secundariamente, como hospedeiro acidental. $\mathrm{Na}$ região neotropical, pelo menos 40 espécies de mamíferos silvestres, principalmente roedores, marsupiais e desdentados, já foram encontrados naturalmente infectados por Leishmania, mas poucas são reconhecidas como reservatórios primários (LAINSON e SHAW 1987; GRIMALDI e col. 1989). Na mesma região, os flebotomíneos são representados por cerca de 460 espécies, mas poucas foram encontradas naturalmente infectadas e, destas, só algumas são vetoras comprovadas (LAINSON e SHAW 1987; SHAW e LAINSON 1987; GRIMALDI e col. 1989; KILLICK-KENDRICK 1990).

Uma série de estudos realizados em regiões endêmicas do Brasil permitiu elucidar diversos ciclos de transmissão das leishmanioses tegumentares (SHAW e 
LAINSON 1987), no entanto, ainda existem regiões onde o próprio homem infectado aparece como indicador da existência da zoonose e os vetores e reservatórios não são conhecidos. Este último quadro pode ser exemplificado pela Leishmania (Viannia) braziliensis, amplamente distribuída pelo Brasil, provavelmente representada por um complexo de espécies e sub-espécies não separadas pelos métodos usuais de identificação (LAINSON 1989; LAINSON e col. 1994). Em região de floresta primária do Pará, o vetor comprovado é Lutzomyia wellcomei, espécie altamente antropofilica e de hábito diurno e noturno, entretanto o reservatório silvestre, provavelmente um roedor, ainda não foi determinado (LAINSON 1989). Em certas regiões de Minas Gerais, Bahia, Pernambuco e Ceará, Lutzomyia whitmani parece estar adaptada ao ambiente modificado e é apontada como provável vetora de Leishmania braziliensis ao homem e animais domésticos (MAYRINK e col. 1979; VEXENAT e col. 1986; BRANDÃO-FILHHO e col. 1994; PASSOS e col. 1993; QUEIROZ e col. 1994; AZEVEDO e col. 1996).

Na Região Sudeste do Brasil, particularmente, nos Estados de São Paulo e Rio de Janeiro, a intensa devastação das florestas tem confinado Leishmania braziliensis a refúgios enzoóticos representados por matas residuais e parece ser transmitida ao homem e animais domésticos por um número restrito de espécies de flebotomíneos, que demonstram graus variados de adaptação ao ambiente antrópico alterado e domiciliar (GOMES 1994; LAINSON e col. 1994). Lutzomyia. intermedia espécie de reconhecido comportamento antropofilico e capacidade de adaptação ao ambiente domiciliar, apresenta-se predominante nesta região e, tem sido apontada como responsável pela transmissão da LTA ao homem (FORATTINI e col. 1976; ROCHA E SILVA e col. 1980; GOMES e col. 1983; 1986; 1989; GOMES e 
GALATI 1987; GOMES 1992; LEOPOLDO E SILVA e col. 1984; RANGEL e col. 1984; 1986; 1990; TANIGUCHI e col. 1991; CASANOVA e col. 1995; SUCEN'; CAMARGO-NEVES 1999). Recentemente, estudos morfométricos e genéticos revelaram que Lutzomyia intermedia no Brasil pode estar representada por um complexo de espécies constituído, até o momento, por duas espécies: Lutzomyıa intermedia s.s. e Lutzomyia neivai (MARCONDES, 1996; 1997; MARCONDES e col. 1998). No presente estudo, o complexo não foi considerado e a denominação de taxon adotada foi Lutzomyia intermedia s.l..

Entretanto, considerando-se ainda, a Região SE do Brasil, a presença de outras espécies antropofilicas como L. whitmani, Lutzomyia. pessoai, Lutzomyia. migonei e Lutzomyia fischeri no interior das matas remanescentes e no ambiente domiciliar de localidades endêmicas (MAYRINK e col. 1979; RANGEL e col. 1986; GOMES e col. 1989; TANIGUCHI e col. 1991; TOLEZANO 1994; FALQUETO 1995; MAYO e col. 1998; SUCEN ${ }^{1}$; CAMARGO-NEVES 1999) não permite descartar a possibilidade de participação das mesmas no ciclo de transmissão ao homem e, principalmente, na manutenção do ciclo enzoótico. Excetuando L. fischeri. todas as outras espécies referidas já foram encontradas naturalmente infectadas em áreas endêmicas do Estado de São Paulo.

Coletas realizadas na região do vale do rio Mogi Guaçu também evidenciaram a predominância de $L$. intermedia s.l., em áreas de vegetação degradada, e de $L$. whitmani e L. pessoai, em áreas de florestas menos impactadas (FORATTINI e col. 1976; GOMES e col. 1989; TEODORO e col. 1983; CASANOVA e col. 1995).

\footnotetext{
' Superintendência de Controle de Endemias-São Paulo: Relatório do Grupo de Trabalho de Revisão do Sistema de Vigilância da LTA no Estado de São Paulo, 1997.
} 
Nessa mesma região, FORATTINI e col. $(1972 \mathrm{a} ; 1972 \mathrm{~b} ; 1973)$ isolaram de três espécies de roedores e de L. intermedia s.l. e L. pessoai, Leishmania (provavelmente Leishmania braziliensis) identificada somente por caracteres extrínsecos tais como, a característica de crescimento em meio de cultura e evolução da infecção em animais de laboratório. No entanto, o caráter único desses encontros só permite considerá-los como potenciais reservatórios ou vetores de Leishmania, respectivamente. CASANOVA e col. 1995, na mesma área do presente estudo, detectaram a presença de flagelados indistinguiveis de formas promastigotas de Leishmania, em quatro fềmeas de L. intermedia s.l.

Pode-se considerar que, embora envolvendo várias espécies de Leishmania, mamíferos reservatórios e flebotomíneos vetores, as diferentes epidemiologias das leishmanioses tegumentares do Novo Mundo parecem seguir um padrão básico similar, onde a amplitude de ambientes ocupada pelo vetor e o seu hábito alimentar são considerados determinantes no elo de ligação entre o homem e o ciclo enzoótico (SHAW e LAINSON 1987). No Estado de São Paulo, a epidemiologia da LTA, mesmo que intensivamente investigada, ainda apresenta elos obscuros, como o desconhecimento do(s) reservatório(s) e a confirmação da(s) espécie(s) vetora(s), que dificultam o conhecimento do ciclo de transmissão da Leishmania braziliensis.

\subsection{Parâmetros ecológicos para a transmissão da LTA}

O critério essencial para determinação de um vetor de leishmaniose é o isolamento repetitivo de Leishmania sp., indistinguivel daquela que provoca a infecção humana, em flebotomineos antropofilicos, da mesma área de distribuição (KILLICK-KENDRICK e WARD 1981; YOUNG e LAWYER 1987; LAIN SON e 
SHAW 1987; KILLICK-KENDRICK 1990). Evidências complementares são dadas pela distribuição espacial coincidente com a distribuição de casos de leishmaniose e pela competência em manter todas as etapas do desenvolvimento parasitário e transmitir, experimentalmente, o parasita pela picada (KILLICK-KENDRICK e WARD 1981; KILLICK-KENDRICK 1990).

Poucos isolamentos de Leishmania em flebotomíneos têm sido alcançados na Região Sudeste do Brasil e os mesmos não foram caracterizados satisfatoriamente (FORATTINI e col. 1972b; RANGEL e col. 1984; CASANOVA e col. 1995). Ainda são necessárias pesquisas de isolamento e identificação das leishmanias que infectam o homem e flebotomíneos, para que seja definitivamente esclarecido o papel vetorial das diferentes espécies antropofilicas. $\mathrm{Na}$ ausência desta comprovação, praticamente apenas dois parâmetros ecológicos, a antropofilia e a abundância populacional, têm sido utilizados como evidências epidemiológicas para apontar uma espécie de flebotomíneo como vetor. No entanto, outros parâmetros biológicos e ecológicos dos vetores tais como: expectativa de vida; ciclo gonotrófico; comportamento alimentar; dispersão e criadouros naturais, deveriam ser melhores conhecidos, para se obter um entendimento mais completo sobre a circulação da Leishmania na natureza (KILLICK-KENDRICK 1991). Alguns destes parâmetros são utilizados na avaliação da capacidade vetorial de uma espécie.

Por definição, a capacidade vetorial é o número de novas infecções disseminadas por caso, por dia, por um vetor, e é estimada a partir dos parâmetros de abundância populacional, sobrevivência diária e padrão e taxa de alimentação sanguinea do vetor (GARRET-JONES 1964; REISEN 1989). O conhecimento de tais parâmetros permite avaliar a relação entre os diferentes fatores associados às 
epidemiologias de transmissão. A sobrevivência determina a abundância populacional e a duração da vida infectiva e infectante do vetor; a duração do ciclo gonotrófico, definido pelo período de tempo entre um repasto sanguíneo e a oviposição, permite estimar a freqüência com que ocorrem as alimentações sanguineas realizadas por uma fềmea; o hábito alimentar indica o grau de antropofilia ou zoofilia do vetor.

Experimentos de marcação-soltura-recaptura são os mais freqüentemente utilizados para estimar os parâmetros de tamanho populacional, sobrevivência, duração do ciclo gonotrófico e taxas de imigração e emigração, todos considerados como componentes "chave" na determinação da capacidade vetorial (GARRETJONES 1964; NELSON e col. 1978 MILBY e REISEN 1989; REISEN 1989, REISEN e col. $1981 ; 1991)$.

Mais comumente, as estimativas dos parâmetros da capacidade vetorial têm sido orientadas para culicídeos vetores da malária e de arboviroses (NELSON e col. 1978; REISEN e col 1979; 1981; 1991; REISEN e BOREHAM 1982; REISEN e LOTHROP 1995; JENSEN e WASHINO 1991; SANTOS 2001).

Para flebotomineos, tem sido salientada a falta de conhecimentos sobre os parâmetros da capacidade vetorial (KILLICK-KENDRICK 1978; 1991; LISENKO e BELJAEV 1987). Estudos sobre sobrevivência diária, tamanho populacional absoluto e duração do ciclo gonotrófico na natureza, ainda não foram realizados para espécies deste grupo. Por outro lado, o comportamento alimentar das fêmeas de flebotomíneos tem sido melhor investigado.

O conhecimento do hábito alimentar dos flebotomíneos de uma área endêmica pode evidenciar, indiretamente, os prováveis hospedeiros reservatórios ou, ao contrário, quando este já é conhecido, levantar suspeitas sobre as espécies vetoras 
(CHRISTENSEN e col. 1982; GUY e col. 1984; SHAW e LAINSON 1987; YOUNG e LAWYER 1987; GRIMALDI e col. 1989; LAINSON e col. 1994). Neste sentido, a identificação do sangue ingerido por fềmeas encontradas naturalmente ingurgitadas poderia refletir melhor o papel natural desses insetos e de seus hospedeiros como vetores e reservatórios, respectivamente, em diferentes ciclos de transmissão da leishmaniose tegumentar (TESH e col. 1971; CHRISTENSEN e VASQUEZ 1982; CHRISTENSEN e col. 1982; 1983; LEWIS e WARD 1987; YOUNG e LAWYER 1987; MORRISON e col. 1993).

Os trabalhos de revisão de TEMPELIS (1975) e WASHINO e TEMPELIS (1983) mostram as diversas técnicas sorológicas que vêm sendo utilizadas nos estudos sobre o reconhecimento do sangue ingerido por artrópodes. Entre essas, a técnica de reação de precipitação desenvolvida por $\operatorname{WEITZ}(1956,1960)$, tem sido modificada e utilizada em estudos sobre o hábito alimentar de flebotomíneos (TESH e col. 1971; 1972; CHRISTENSEN e col. 1982; CHRISTENSEN e VASQUEZ 1982; GUY e col. 1984, MORRISON e col. 1993). No Brasil, excluindo-se o estudo de CHRISTENSEN e col. (1982) na Amazônia, não existem investigações sobre o hábito alimentar de flebotomíneos, pelo reconhecimento do sangue ingerido pelas fềmeas.

O conhecimento das preferências alimentares de flebotomíneos também pode ser alcançado, por coletas comparativas realizadas sobre diferentes iscas animais (DISNEY 1966; THATCHER e HERTIG 1966; THATCHER 1968; SHAW e LAINSON 1968; CHRISTENSEN e col. 1983; AGUIAR e col. 1986; 1987; FALQUETO e col. 1985; FALQUETTO 1995; RANGEL e col. 1990). Excluindo-se os estudos que visaram investigar a antropofilia (GOMES e col. 1983; GOMES e 
GALATI 1989), praticamente, não existem investigações da atratividade de iscas animais sobre populações de flebotomíneos no Estado de São Paulo.

O padrão de dispersão ou, simplesmente, amplitude de vôo dos flebotomíneos em áreas endêmicas, pode contribuir para o entendimento da epidemiologia das leishmanioses (KILLICK-KENDRICK 1978; KILLICK-KENDRICK e col. 1984; LAINSON 1989). O comportamento de dispersão está relacionado com a determinação do grau de contato entre os vetores e os hospedeiros mamíferos e o seu conhecimento também tem sido considerado como pré-requisito no planejamento de medidas de controle em áreas endêmicas (KILLICK-KENDRICK e col. 1984; ALEXANDER e YOUNG 1992; MUTINGA e col. 1992). Experimentos de marcação-soltura-recaptura fornecem os melhores meios para estimar o padrão e amplitude de vôo. Os poucos estudos realizados com marcação-soltura-recaptura de flebotomíneos na região neotropical têm evidenciado amplitude de vôo dissimilar para diferentes espécies de flebotomíneos em diferentes tipos de ambientes (CHANIOTIS e col. 1974; ALEXANDER e YOUNG 1992; ALEXANDER 1987; MORRISON e col. 1993). Na região Amazônica foram obtidas informações sobre a amplitude de vôo de Lutzomyia longipalpis (DYE e col. (1991) no entanto, não existem dados de dispersão para outras espécies de flebotomíneos no Brasil.

No presente estudo, pretendeu-se identificar características ecológicas das populações de L. intermedia s.l., com ênfase na distribuição sazonal e espacial, dispersão, comportamento alimentar e estimativas de sobrevivência e densidade absoluta, que contribuam para o esclarecimento dos mecanismos de transmissão da leishmaniose tegumentar americana em área endêmica rural do Vale do Rio Mogi Guaçu. Estudos realizados na região demonstraram a presença predominan 
intermedia s.l. entre os potenciais vetores da LTA (GOMES e col. 1989; CASANOVA e col. 1995). 


\section{OBJETIVOS}

\subsection{Objetivo Geral}

Avaliar o potencial de $L$. intermedia $s$. $l$. atuar como vetor da leishmaniose tegumentar americana, por meio de estimativas de parâmetros da capacidade vetorial de populações da zona rural do município de Conchal.

\subsection{Objetivos Específicos}

Estudou-se a população de Lutzomyia intermedia s.l. da zona rural do município de Conchal com os seguintes objetivos:

- Caracterizar a distribuição mensal e espacial

- Determinar o padrão de dispersão

- Estimar parâmetros populacionais, tais como: sobrevivência diária, tamanho absoluto e taxas de adição e de perda

- Estimar a duração do ciclo gonotrófico

- Identificar o comportamento alimentar 


\section{MATERIAL E MÉTODOS}

\section{1. Área de estudo}

O estudo foi realizado numa localidade da zona rural do municipio de Conchal (bairro Arurá), Estado de São Paulo. Conchal (22 $18^{\prime}$ ' S e $47^{\circ} 13^{\prime} \mathrm{W}$ ) está situada na bacia do rio Mogi Guaçu onde a LTA é endêmica (figura 1). O rio Mogi Guaçu, nesta região, apresenta características de um curso d'água de planície, com curvas sinuosas

e longas. A cobertura vegetal, representada pela floresta estacional semidecidual (Veloso e col. 1991), tem sofrido drástica redução, e atualmente se restringe a pequenos fragmentos de mata ciliar.

O clima da região é do tipo mesotérmico de inverno seco (CWA- classificação Climática de Koeppen) apresentando uma estação quente e úmida, entre outubro e março, e uma estação mais fria e seca entre abril e setembro. A precipitação pluviométrica média anual é de $1.381 \mathrm{~mm}$ e a temperatura média anual é de $21,6^{\circ} \mathrm{C}$.

A área onde foi realizado o estudo é caracterizada por intensa atividade agrícola e pela presença de remanescentes florestais ao longo das margens do rio Mogi Guaçu, com dossel variando entre 15 e $20 \mathrm{~m}$ de altura. Inundações da mata ciliar pelas águas do rio ocorrem comumente na estação chuvosa. Diversas chácaras e ranchos de pescaria estão distribuídos pela área e, embora o plantio da laranja seja predominante, também são comuns pomares, hortaliças e a criação de aves e porcos.

Cinco chácaras, e o remanescente de mata ciliar contíguo a elas, foram utilizados para a realização dos experimentos em campo e coletas de flebotomíneos. As residências das chácaras estão localizadas próximas à mata ciliar, entre 50 e 70 metros de distância (figura 2). 


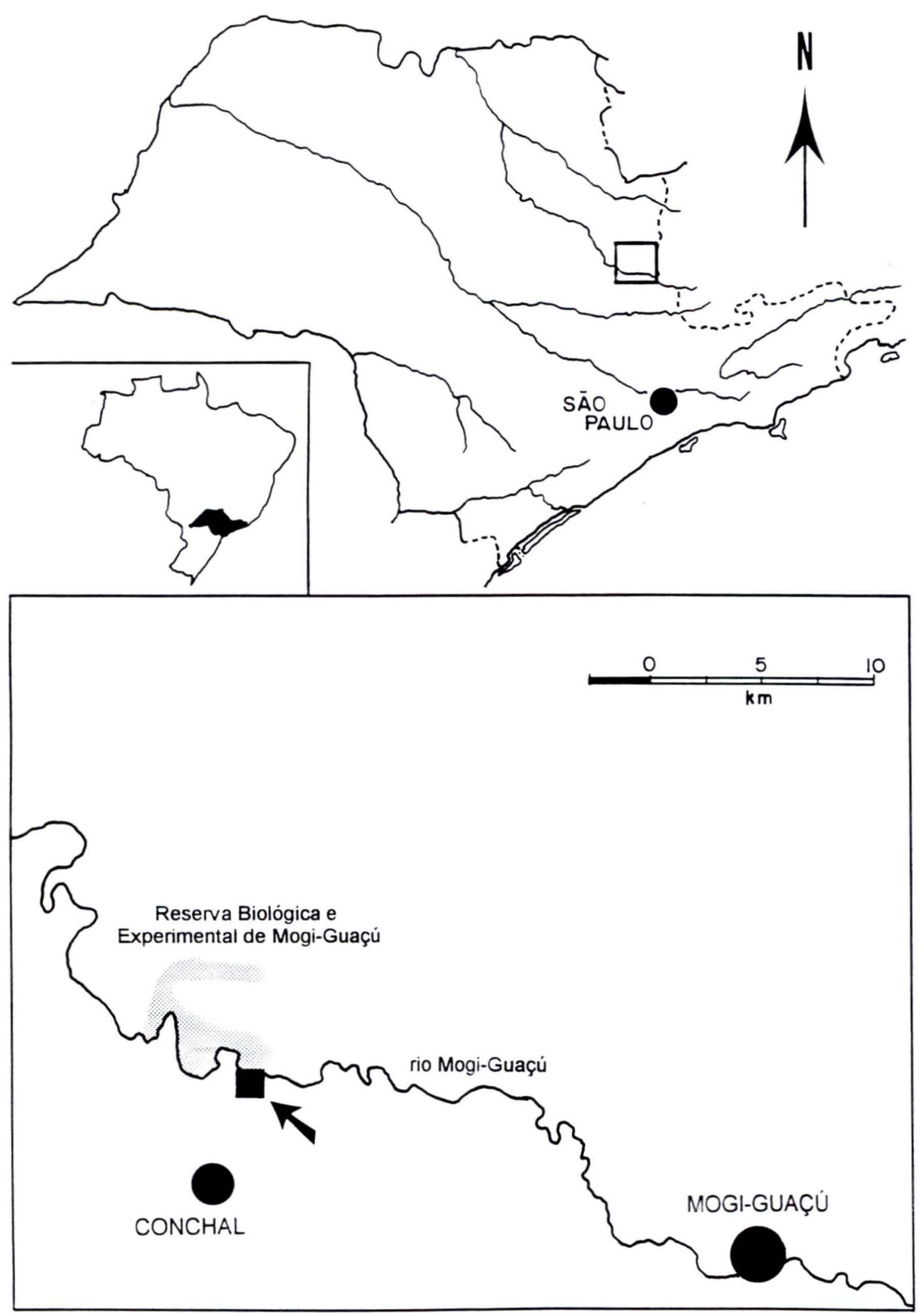

Figura 1. Localização geográfica da área de estudo no município de Conchal, Estado de São Paulo, Brasil. 


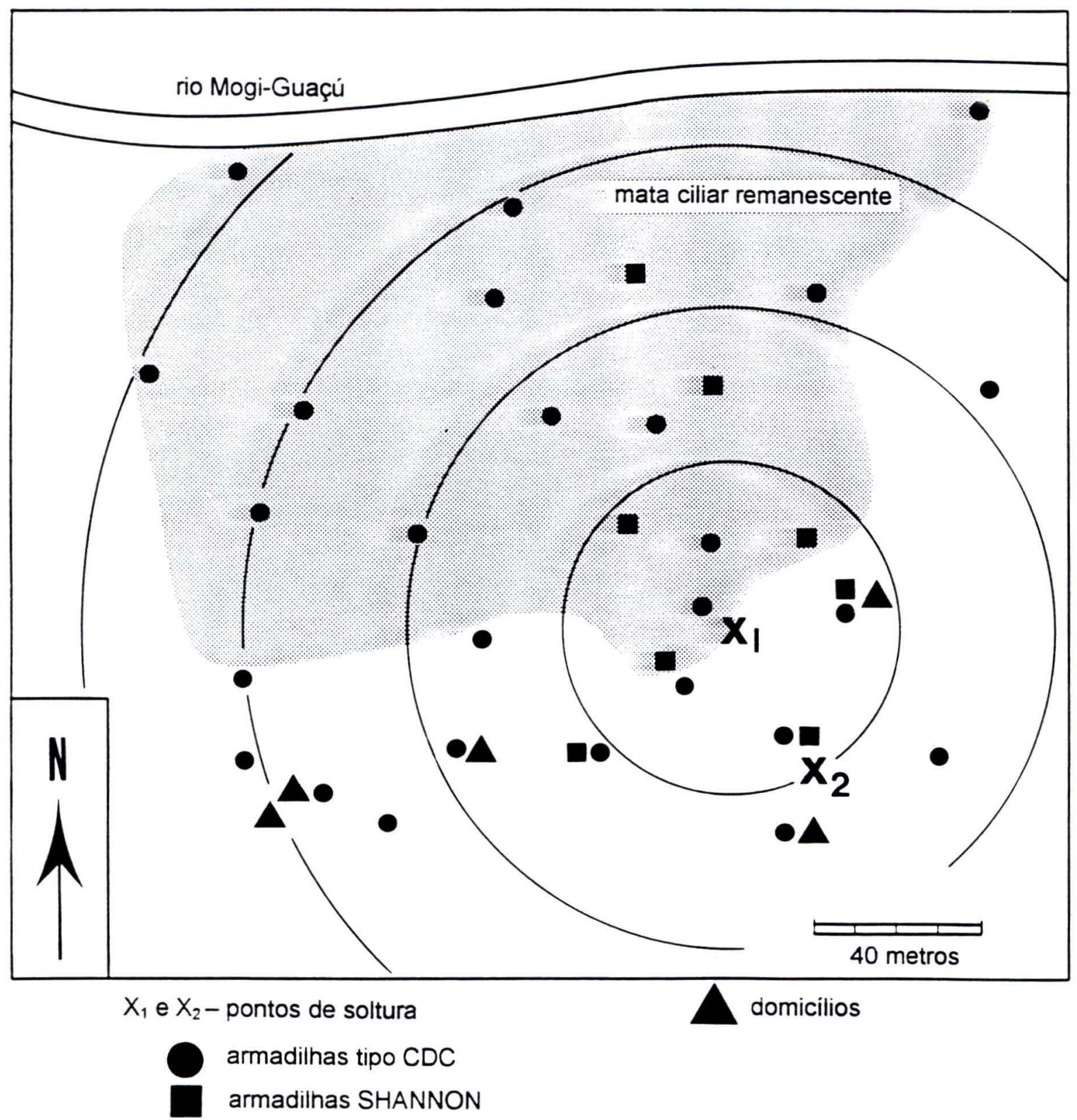

Figura 2. Representação esquemática da área de estudo localizada na margem esquerda do rio Mogi Guaçu, na área rural do município de Conchal, SP. 


\subsection{Período de estudo}

Os estudos foram realizados no período de maio de 1999 a abril de 2000 . Todavia, nas investigações referentes ao hábito alimentar foram incluídos os dados obtidos entre setembro de 1994 e agosto de 1995.

\subsection{Dados meteorológicos}

Os dados de precipitação pluviométrica (milímetros de chuva), temperatura do ar $\left({ }^{\circ} \mathrm{C}\right)$ e direção do vento foram fornecidos pelo Posto Meteorológico da Estação Experimental de Mogi Guaçu - administrada pelo Instituto Florestal do Estado de São Paulo. O Posto Meteorológico está situado a aproximadamente $3 \mathrm{Km}$ da área de estudo.

\subsection{Coletas de flebotomíneos adultos}

Uma série de atividades foi realizada em campo para: a) caracterizar a abundância das espécies de flebotomíneos presentes na área de estudo; b) caracterizar a variação sazonal e temporal, e o comportamento alimentar de $L$. intermedia s.l.; c) estimar a dispersão, a taxa de sobrevivência diária e o tamanho populacional de $L$. intermedia s.l., bem como a duração do seu ciclo gonotrófico.

Os ambientes investigados, a periodicidade e as técnicas utilizadas para a coleta dos flebotomíneos no campo variaram de acordo com os objetivos dos estudos. 


\subsection{Distribuição espacial e temporal}

Para caracterizar a composição de espécies de flebotomíneos e a distribuição espacial e temporal de $L$. intermedia s.l. presentes na área de estudo foram realizadas coletas mensais de adultos, em diversos ambientes e no período de maio de 1999 a abril de 2000, utilizando-se armadilhas tipo CDC (SERVICE 1993) e armadilhas de Shannon, modificadas pela retirada do compartimento central das mesmas (VEXANET e col. 1986), (quadro I).

Quadro I. Resumo das técnicas, horas de coleta e ambientes pesquisados para identificar a fauna de flebotomíneos e a distribuição espacial e temporal de $L$. intermedia s.l., na zona rural de Conchal, no período de maio de 1999 a abril de 2000

\begin{tabular}{|c|c|c|c|c|c|}
\hline Técnica & Ambiente & $\begin{array}{c}\mathrm{N}^{\circ} \mathrm{de} \\
\text { coletas }\end{array}$ & $\begin{array}{c}\mathrm{N}^{\circ} \text { de } \\
\text { armadilhas/coleta }\end{array}$ & Horas/coleta & $\begin{array}{c}\text { Total de } \\
\text { horas }\end{array}$ \\
\hline \multirow{4}{*}{$\begin{array}{c}\text { Armadilha } \\
\text { CDC }\end{array}$} & Mata copa & 12 & 2 & 12 & 288 \\
\cline { 2 - 6 } & Mata solo & 12 & 2 & 12 & 288 \\
\cline { 2 - 6 } & Margem mata & 12 & 2 & 12 & 288 \\
\cline { 2 - 6 } & Aberto & 12 & 2 & 12 & 288 \\
\cline { 2 - 6 } & Peridomicilio & 12 & 2 & 12 & 288 \\
\cline { 2 - 6 } & Varanda & 12 & 2 & 12 & 288 \\
\hline \multirow{3}{*}{$\begin{array}{c}\text { Armadilha } \\
\text { Shannon }\end{array}$} & Mata solo & 12 & 2 & 3 & 72 \\
\cline { 2 - 6 } & Margem mata & 12 & 2 & 3 & 72 \\
\cline { 2 - 6 } & Peridomicilio & 12 & 2 & 3 & 72 \\
\hline
\end{tabular}


As armadilhas tipo CDC foram instaladas, entre as 18:00 e 6:00 horas, na varanda e peridomicílio (até $20 \mathrm{~m}$ ao redor das residências) das residências de duas chácaras, previamente selecionadas, no aberto (entre o peridomicilio e a mata), na margem da mata e no interior da mata, tanto no nível do solo como na copa das árvores. Cada ambiente foi investigado com duas armadilhas, perfazendo um total de 12 armadilhas/noite.

As coletas com armadilhas de Shannon foram realizadas das 18:00 às 21:00 horas, no ambiente peridomiciliar das residências de duas chácaras, na margem da mata e no interior da mata. Cada ambiente foi investigado com duas armadilhas, perfazendo um total de 6 armadilhas/noite.

Para caracterizar a distribuição temporal utilizou-se o número total de indivíduos de $L$. intermedia s.l., coletados nos 2 tipos de armadilhas, a cada mês. Para comparar a abundância dos indivíduos nos diferentes ambientes investigados aplicouse um teste de qui-quadrado aos dados obtidos nas coletas com armadilhas tipo CDC.

\subsection{Dispersão e parâmetros populacionais}

Para estimar os parâmetros populacionais e a dispersão de L. intermedia s.l., na área de estudo, diversos experimentos foram realizados em campo, utilizando-se a técnica de marcação-soltura-recaptura. Tentativas de coletas de flebotomíneos para fazer a marcação foram realizadas, em armadilhas de Shannon, no período de maio de 1999 a abril de 2000, todavia, apenas nos meses de agosto a novembro de 1999 e fevereiro e março de 2000, a população de flebotomíneos apresentou abundância suficiente (acima de 200 flebotomíneos coletados) para a realização dos experimentos. 


\subsubsection{Técnica de marcação-soltura-recaptura}

Os flebotomíneos utilizados nos experimentos de marcação-soltura-recaptura foram coletados no período noturno, das 18:00 às 21:00 horas, com aparelho sugador manual (aspirador de Castro) em armadilhas de Shannon instaladas em diversos ambientes (peridomicílio, margem mata e interior da mata). Os indivíduos coletados eram contados e transferidos para caixas de isopor, forradas com gesso umedecido. Ao final da coleta, os indivíduos eram marcados borrifando-se pó fluorescente (Bioquip Products Inc.) para dentro da caixa. Foram utilizadas diferentes cores (vermelho, amarelo, azul e branco) para marcar os flebototomíneos de acordo com o local e a data de soltura ou, quando era o caso, para diferenciar as fềmeas grávidas. No momento da soltura, realizada imediatamente após a marcação, a tampa era retirada e a caixa agitada, mas nunca invertida, para induzir o vôo dos flebotomíneos para o ambiente. Dois pontos de soltura dos indivíduos marcados foram utilizados: margem da mata e peridomicilio. No entanto a soltura no peridomicilio ocorreu apenas no primeiro experimento do mês de agosto de 1999 e no experimento de abril de 2000 .

Tentativas de recaptura dos flebotomíneos marcados (quadro 2) foram feitas com o uso de 6 armadilhas de Shannon, entre as 18:00 às 21:00 horas, durante 5 a 7 noites consecutivas, contadas a partir da noite seguinte à soltura dos flebotomíneos, à exceção do primeiro experimento do mês de agosto de 1999 , quando as recapturas foram realizadas em apenas 2 noites. Duas armadilhas foram colocadas em cada ambiente (peridomiciliar, margem da mata e mata), à exceção do primeiro experimento do mês de agosto de 1999, onde foram utilizadas apenas 2 armadilhas no peridomicílo e 1 armadilha na margem da mata e mata. As armadilhas dista m entre 
25 e 90 metros do ponto central de soltura, situado na margem da mata. Todas as coletas tiveram a participação de três pessoas como coletores.

Tentativas de recaptura também foram realizadas com o uso de 16 a 20 armadilhas tipo $\mathrm{CDC}$, utilizadas por pelo menos 3 noites a partir da noite da soltura, entre as 18:00 e 6:00 horas (quadro 2). Estas armadilhas estiveram distribuídas entre 5 e $160 \mathrm{~m}$ do ponto de soltura situado na margem da mata, e amostraram o ambiente varanda, peridomiciliar, aberto, margem da mata e mata solo.

Quadro II. Resumo das técnicas, horas de coleta e ambientes pesquisados, nos experimentos de marcação-soltura-recaptura realizados para estimar parâmetros populacionais, a duração do ciclo gonotrófico e a dispersão de L. intermedia s.l, na zona rural de Conchal, no período de maio de 1999 a abril de 2000.

\begin{tabular}{|c|c|c|c|c|c|}
\hline Técnica & Ambiente & $\begin{array}{l}\mathrm{N}^{\mathrm{o}} \mathrm{de} \\
\text { coletas }\end{array}$ & $\begin{array}{c}\mathrm{N}^{\mathrm{o}} \mathrm{de} \\
\text { armadilhas/coleta }\end{array}$ & Horas/coleta & $\begin{array}{c}\text { Total de } \\
\text { horas }\end{array}$ \\
\hline \multirow{5}{*}{$\begin{array}{l}\text { Armadilha } \\
\text { CDC }\end{array}$} & Mata solo & 21 & 4 & 12 & 1008 \\
\hline & Margem mata & 21 & 4 & 12 & 1008 \\
\hline & Aberto & 21 & 4 & 12 & 1008 \\
\hline & Peridomicílio & 21 & 4 & 12 & 1008 \\
\hline & Varanda & 21 & 4 & 12 & 1008 \\
\hline \multirow{3}{*}{$\begin{array}{l}\text { Armadillha } \\
\text { de Shannon }\end{array}$} & Mata solo & 40 & 2 & 3 & 240 \\
\hline & Margem mata & 40 & 2 & 3 & 240 \\
\hline & Peridomicilio & 42 & 2 & 3 & 252 \\
\hline
\end{tabular}


Todos os flebotomíneos coletados foram levados ao laboratório e examinados em estereomicroscópio sob "black light blue", para triagem dos exemplares marcados com pó fluorescente.

\subsubsection{Avaliação do efeito do pó fluorescente na sobrevivência dos}

\section{flebotomíneos}

A avaliação do efeito do pó fluorescente sobre a sobrevivência dos flebotomíneos foi realizada, em condições de laboratório, pela comparação das taxas de sobrevivência diária entre grupos de flebotomíneos marcados e não marcados (controle) (REISEN e ASLAMKHAN 1979; PARDO e col. 1996).

Utilizando-se flebotomíneos coletados no campo, separou-se um grupo de 30 individuos machos e 40 fềmeas, em uma caixa de isopor forrada com gesso umedecido, para serem borrifados com pó fluorescente. Outro grupo de 30 flebotomíneos machos e 40 fềmeas foi colocado em outra caixa de isopor para servir de controle ao experimento. Após a marcação, os flebotomíneos de ambas as caixas foram transferidos para duas gaiolas e algodão embebido em solução açucarada foi oferecido como alimento. Após a transferência para as gaiolas, e por um período de 10 dias consecutivos, os flebotomíneos eram observados a cada 8 horas, para verificação e contagem do número de indivíduos mortos. Duas séries deste experimento foram realizadas: uma em abril e outra em maio de 1999.

Os coeficientes de regressão do número de sobreviventes diários foram testados para diferença significativa de zero por meio de análise de variância (ANOVA) e comparados com análise de covariância (ANCOVA). 


\subsubsection{Estimativas de dispersão}

A média aritmética e a mediana da distância de dispersão foram estimadas levando-se em conta o número de indivíduos machos e de fềmeas de L. intermedia s.l. recapturados nas armadilhas CDC, dispostas entre 5 e $160 \mathrm{~m}$ de distância do ponto de soltura, abrangendo os diversos ambientes investigados (figura 1).

As recapturas nas armadilhas CDC do mês de novembro de 1999 foram utilizadas para medir a distância média de dispersão diária de L. intermedia s.l.. O número de machos e de fềmeas recapturados nas armadilhas, dispostas entre anéis concêntricos de $40 \mathrm{~m}$, a partir do ponto central de soltura, foi agrupado e ajustado por um fator de correção que elimina a queda na densidade de armadilhas com o aumento da distância. Portanto, este fator permite estimar o número médio recapturado, por áreas iguais de amostragem (BRENNER e col. 1984; SERVICE 1993). O fator de correção (FC) utilizado foi:

$$
\mathrm{FC}=\mathrm{A}_{\mathrm{n}} \cdot \mathrm{N}_{\mathrm{a}} / \mathrm{A}_{\mathrm{t}}
$$

Onde:

$\mathrm{FC}=$ fator de correção;

$\mathrm{A}_{\mathrm{n}}=$ área de cada anel;

$\mathrm{A}_{\mathbf{4}}=$ área total de amostragem;

$\mathrm{N}_{\mathrm{a}}=$ número de armadilhas utilizadas durante a investigação.

A distância média de dispersão diária (DMD) foi, então, estimada pela equação: $\mathrm{DMD}=\sum$ (Número coletado corrigido $\mathrm{x}$ Distância $/$ Número total corrigido). 
Para testar possíveis diferenças na direção de dispersão a partir do ponto de soltura central, situado na margem da mata, o número de machos e fềmeas recapturados, nas armadilhas de Shannon, situadas na mata solo, margem mata e peridomicílio, foi analizado por um teste de qui-quadrado.

\subsubsection{Estimativas da sobrevivência diária}

A sobrevivência foi considerada constante durante os períodos de recaptura e foi estimada pela regressão do número de exemplares de L. intermedia s.l. recapturados, transformados em $\ln (y+1)$, em função dos dias corridos após a soltura (GILLIES 1961; NELSON e col. 1978; MILBY e REISEN 1989), isto é:

$$
\mathrm{m}_{\mathrm{t}}=\mathrm{M}_{\mathrm{o}} \mathrm{rs}^{\mathrm{t}}
$$

onde:

$\mathrm{m}_{\mathrm{t}}=$ número de indivíduos marcados recapturados em cada dia;

$\mathrm{M}_{0}$ = número de indivíduos marcados e soltos;

$r$ = taxa de amostragem;

$\mathrm{S}=$ taxa diária de sobrevivência;

$\mathrm{t}=\mathrm{tempo}($ dias $)$

ou, mais facilmente pela sua transformação logarítmica:

$$
\ln \mathrm{m}_{\mathrm{t}}=\ln \left(\mathrm{M}_{0} \mathrm{r}\right)+\mathrm{t} \ln \mathrm{s}
$$


Assim, a sobrevivência ( $s$ ) foi calculada pela expressão $s=e^{b}$, onde $e=$ base do logarítmo natural e b = coeficiente de regressão (GILLES 1961; NELSON e col. 1978; REISEN e col. 1980; KRAMER e col. 1995; TAKKEN e col. 1998).

\subsubsection{Estimativa do tamanho populacional, taxa de adição e taxa de perda}

O tamanho absoluto da população foi calculado diariamente, usando a modificação do Índice de Lincoln (BAILEY 1952) ajustado para taxas de recaptura baixas e incluindo a sobrevivência na estimativa. A população mensal foi estimada pela média das estimativas diárias com a variância igual à média da variância das estimativas diárias:

$$
N_{t}=\left(n_{t}+1\right) M_{t} /\left(m_{t}+1\right)
$$

Com, $M_{t}=\left(M_{0}-\sum m_{t}\right) s^{t}$

e, variância: $\operatorname{Var} N_{t}=\left(M_{t}\right)^{2}\left(n_{t}+1\right)\left(n_{t}-m_{t}\right) /\left(m_{t}+1\right)^{2}\left(m_{t}+2\right)$

onde: $\mathrm{N}_{\mathrm{t}}=$ população absoluta estimada;

$\mathrm{n}_{\mathrm{t}}=$ número de indivíduos coletados;

$\mathrm{m}_{\mathrm{t}}=$ número de indivíduos marcados recapturados;

$\mathrm{M}_{\mathrm{t}}=$ número de individuos marcados que permanecem na população.

$\mathrm{M}_{0}$ = número de indivíduos marcados e soltos;

s = taxa diária de sobrevivência;

$\mathrm{t}=$ tempo $($ dias $)$ 
A adição diária da população foi obtida pela diferença entre as estimativas populacionais diárias, levando-se em conta a sobrevivência (MANLY e PARR 1968; REISEN e col. 1991;1992):

$$
A_{t}=N_{t}-s N_{t-1}
$$

onde:

$A_{t}=$ adição diária;

$\mathrm{N}_{\mathrm{t}}=$ população absoluta estimada;

$\mathrm{s}=$ taxa diária de sobrevivência;

$t=$ tempo $($ dias $)$

com taxa de adição diária (Ta) igual a: $T a=A_{t} / N_{t}$ A taxa de perda (Tp) foi calculada subtraindo a taxa de sobrevivência (s) de 1: Tp = 1 - s. Portanto, a taxa de mudança da população a cada dia pode ser estimada: $\mathrm{Tm}=\mathrm{Ta}-\mathrm{Tp}$. Estimativas mensais destes parâmetros foram obtidos pelas médias das estimativas diárias dos mesmos.

\subsection{Ciclo gonotrófico}

A duração do ciclo gonotrófico foi estimada com a soltura de fềmeas ingurgitadas marcadas com pó fluorescente, nos meses de novembro de 1999 e fevereiro de 2000. As fềmeas utilizadas nos experimentos eram originárias do campo e foram alimentadas, no laboratório, em pintos, na noite anterior a marcação e soltura. A soltura das fềmeas, se deu na margem da mata, juntamente com a soltura dos indivíduos utilizados nos experimentos de estimativas da dispersão e dos parâmetros 
populacionais. As recapturas foram realizadas com as mesmas armadilhas de Shannon e CDC e nos mesmos periodos e ambientes utilizadas naqueles experimentos.

\subsection{Comportamento Alimentar}

Dois parâmetros de comportamento alimentar das fềmeas de L. intermedia s.... foram investigados: a preferência alimentar e o hábito alimentar.

\subsubsection{Preferência Alimentar}

Os experimentos sobre preferência alimentar foram realizados nos meses de agosto e novembro de 1999 e fevereiro e abril de 2000. Armadilhas tipo Disney (DISNEY 1966), modificadas e associadas com iscas de cão, gambá, roedor e controle (sem isca animal), foram instaladas, entre 18:00 e 6:00 horas, no peridomicílio e na mata da área de estudo (quadro III).

Quadro III. Resumo das horas de coleta e ambientes pesquisados, no experimento sobre preferência alimentar de L. intermedia s.l., realizado na zona rural de Conchal, nos meses de agosto e novembro de 1999 e fevereiro e abril de 2000.

\begin{tabular}{|c|c|c|c|c|c|}
\hline Técnica & Ambiente & $\mathrm{N}^{\circ}$ de & $\mathrm{N}^{\circ}$ de & Horas/coleta & Total de \\
& & coletas & armadilhas/coleta & & horas \\
\hline Armadilha & Mata solo & 16 & 4 & 12 & 768 \\
\cline { 2 - 7 } tipo Disney & Peridomicílio & 16 & 4 & 12 & 768 \\
\hline
\end{tabular}

Cada gaiola contendo um animal, ou o controle, foram assentadas sobre tablados de madeira, com 1,20 m de lado, dispostos a $30 \mathrm{~cm}$ acima do solo e envoltos 
por cercas quadradas de tela de arame, com 1,30 m de lado e 1,0 m de altura. Os tablados ficaram a $6 \mathrm{~m}$ de distância um do outro, formando um quadrado. Os flebotomíneos foram coletados em seis placas de poliestireno, com $50 \mathrm{~cm}$ por $30 \mathrm{~cm}$, untadas com óleo de rícino. Quatro placas foram dispostas em plano horizontal, em volta de cada gaiola e, duas placas, em plano vertical, encostadas em cada gaiola.

Um experimento completo consistiu de coletas realizadas em períodos seguidos de quatro noites, com trocas de posições dos animais a cada noite, seguindo uma distribuição aleatória determinada por quadrados latinos. Foram realizadas quatro repetições em cada ambiente investigado.

Considerando que a distribuição da contagem de dados segue uma distribuição de Poisson, o número de fềmeas coletadas, em cada isca animal, foi transformado em raiz quadrada. Controlando os possíveis fatores de interferência (noite de coleta e posição da isca), a atração exercida pelas diferentes iscas animais (cão, gambá e roedor) e pelo controle (sem isca) foi analisada estatisticamente pelo REGW Multiple Range Test com 5\% de nível de significância.

\subsubsection{Hábito Alimentar}

Para o estudo da determinação do hábito alimentar das fềmeas de $L$. intermedia s.l. foram utilizadas fềmeas ingurgitadas coletadas em dois períodos distintos: setembro de 1994 a agosto de 1995, e agosto a dezembro de 1999. As coletas foram realizadas com aparelho aspirador elétrico no intra e peridomicílio, na margem da mata e interior da mata, entre as 7:00 e 9:00 horas, nos prováveis abrigos naturais encontrados nesses ambientes, tais como paredes internas e externas das residências, galinheiros, troncos de árvores, serrapilheira (quadro IV). No período de 
setembro de 1994 a agosto de 1995 , as coletas foram realizadas quinzenalmente com o uso de um aparelho com $15 \mathrm{~cm}$ de diâmetro ligado a uma bateria de $12 \mathrm{~V}$ (FORATTINI e col. 1987). No período de agosto a dezembro de 1999, as coletas foram realizadas mensalmente com o uso de um aparelho menor, com $6 \mathrm{~cm}$ de diâmetro e ligado a uma bateria de 6 V (NATAL e MARUCCI 1984).

Quadro IV. Resumo das horas de coleta e ambientes pesquisados no estudo sobre hábito alimentar de $L$. intermedia s.l, realizado na zona rural de Conchal, nos períodos de setembro de 1994 a agosto de 1995 e agosto a dezembro de 1999.

\begin{tabular}{|c|c|c|c|c|c|c|c|c|c|}
\hline \multirow{2}{*}{$\begin{array}{l}\text { Técnica } \\
\end{array}$} & \multirow[b]{2}{*}{$\begin{array}{l}\text { Ambien- } \\
\text { te }\end{array}$} & \multicolumn{4}{|c|}{$\begin{array}{c}\text { Período: setembro/94- } \\
\text { agosto/95 }\end{array}$} & \multicolumn{4}{|c|}{$\begin{array}{c}\text { Período: agosto/99- } \\
\text { dezembro/99 }\end{array}$} \\
\hline & & $\begin{array}{l}\mathrm{N}^{\circ} \mathrm{de} \\
\text { coletas }\end{array}$ & $\begin{array}{l}\mathrm{N}^{\circ} \text { de } \\
\text { arma- } \\
\text { dilhas/ } \\
\text { coleta }\end{array}$ & $\begin{array}{l}\text { Horas } \\
\text { /coleta }\end{array}$ & $\begin{array}{c}\text { Total } \\
\text { de } \\
\text { horas }\end{array}$ & $\begin{array}{l}\mathrm{N}^{\circ} \text { de } \\
\text { coletas }\end{array}$ & $\begin{array}{l}\mathrm{N}^{\circ} \text { de } \\
\text { arma- } \\
\text { dilhas/ } \\
\text { coleta }\end{array}$ & $\begin{array}{l}\text { Horas } \\
\text { /coleta }\end{array}$ & $\begin{array}{c}\text { Total } \\
\text { de } \\
\text { horas }\end{array}$ \\
\hline \multirow{4}{*}{$\begin{array}{l}\text { Aspira- } \\
\text { dor } \\
\text { manual }\end{array}$} & Mata solo & 24 & 1 & 0,2 & 8,0 & 5 & 1 & 0,2 & 1,7 \\
\hline & $\begin{array}{l}\text { Margem } \\
\text { mata }\end{array}$ & 24 & 1 & 0,2 & 8,0 & 5 & 1 & 0,2 & 1,7 \\
\hline & $\begin{array}{l}\text { Perido- } \\
\text { micílio }\end{array}$ & 24 & 1 & 0,2 & 8,0 & 5 & 1 & 0,2 & 1,7 \\
\hline & $\begin{array}{l}\text { Intra- } \\
\text { domicilio }\end{array}$ & 24 & 1 & 0,2 & 8,0 & 5 & 1 & 0,2 & 1,7 \\
\hline
\end{tabular}

No laboratório, as fềmeas ingurgitadas foram acondicionadas em pequenos tubos de vidro e mantidas no "freezer" (temperatura de $-20^{\circ}$ ). Individualmente, essas fềmeas foram imersas em água com detergente por cinco minutos e posteriormente foram lavadas por 3 vezes com solução fisiológica a $0,85 \%$. Cada fềmea foi discecada, 
sob estereomicroscópio, em lâmina contendo uma gota de solução fisiológica. A cabeça e os últimos segmentos abdominais de cada fêmea foram separados para posterior identificação da espécie e o restante do inseto foi transferido para tubos de ensaios pequenos, onde foi macerado em $0,15 \mathrm{ml}$ de solução fisiológica.

Após centrifugação, a identificação do sangue ingerido pelas fềmeas fui realizada pela técnica de reação de precipitação em tubo capilar, descrita por SIQUEIRA (1960). Cada amostra foi testada contra a seguinte bateria de anti-soros: humano, ave, gambá, roedor e cão. Os anti-soros foram produzidos em coelhos e os antígenos foram preparados com Alúmen de Potássio. Todos os anti-soros reagiam para diluições do soro homólogo a pelo menos 1:10.000 e não reagiam para diluições dos soros heterólogos a 1:10. 


\section{RESULTADOS}

\subsection{Flebotomíneos da área de estudo}

Durante o período de estudo, maio de 1999 a abril de 2000, 26.817 flebotomíneos foram coletados em armadilhas de Shannon e CDC, sendo 9.280 machos e 17.567 fêmeas, distribuídos por 7 espécies, (tabela 1). Para a identificação das espécies foi seguida a nomenclatura proposta por Young e Duncan (1994).

Tabela 1. Número e porcentagem total de machos e fêmeas das espécies de flebotomíneos coletados em armadilhas de Shannon e CDC, na zona rural do município de Conchal, no período de maio de 1999 a abril de 2000.

\begin{tabular}{lcccccc}
\hline Espécie & \multicolumn{2}{c}{ Shannon } & \multicolumn{2}{c}{ CDC } & \multicolumn{2}{c}{ \% Total } \\
\cline { 2 - 7 } & Machos & Fêmeas & Machos & Fêmeas & Machos & Fêmeas \\
\hline L. intermedia s.l. & 5.852 & 12.338 & 3.349 & 5.123 & 99,1 & 99,7 \\
L. pessoai & 33 & 15 & 12 & 6 & 0,5 & 0,1 \\
L. whitmani & 0 & 2 & 2 & 6 & 0,0 & 0,0 \\
L. aragaoi & 0 & 0 & 24 & 23 & 0,3 & 0,1 \\
L. cortelezzii & 0 & 1 & 0 & 6 & 0,0 & 0,0 \\
L. lenti & 0 & 0 & 0 & 1 & 0,0 & 0,0 \\
B. brumpti & 2 & 2 & 6 & 14 & 0,1 & 0,0 \\
\hline Total & 5.887 & 12.358 & 3.393 & 5.179 & 100,0 & 100,0 \\
\hline
\end{tabular}

A predominância de L. intermedia s.l. foi quase absoluta. Os machos desta espécie representaram $99,1 \%$ e, as fêmeas $99,7 \%$ dos exemplares coletados, de cada sexo. $\mathrm{O}$ número de fềmeas de $L$. intermedia s.l. coletado foi significativamente maior 
que o de machos, tanto nas armadilhas de Shannon como nas armadilhas $\mathrm{CDC}\left(\mathrm{X}^{2}=\right.$ 2.312 e 371 ; respectivamente, $\mathrm{p}<0,001$ ).

\subsection{Distribuição mensal e espacial de $L$. intermedia s.l.}

Os dados obtidos nas coletas com armadilhas de Shannon e CDC mostram que L. intermedia s.l. esteve presente na área de estudo em todos os meses pesquisados, maio de 1999 a abril de 2000 (tabela 2). No entanto, pode-se perceber que a abundância começa a aumentar no mês de agosto, último mês do período mais frio e seco do ano, e atinge um pico em novembro, mês que antecede o início da estação mais quente e úmida (figuras 3 e 4). Após uma queda durante o período mais chuvoso do ano, a abundância voltou a aumentar no final do mês de fevereiro, e em abril, quando as chuvas e as temperaturas apresentam-se mais amenas, comparativamente ao período anterior (figuras 3 e 4). Embora a área total da mata e parte do peridomicílio, tenham sido inundados por 7 dias no início de janeiro de 2000 e por 3 dias na segunda semana do mês de fevereiro, observou-se um aumento da abundância no final deste último mês. 
Tabela 2. Distribuição mensal do número de machos e fềmeas de L. intermedia s.l. coletados em armadilhas de Shannon e CDC, na zona rural do município de Conchal, no período de maio de 1999 e abril de 2000.

\begin{tabular}{|c|c|c|c|c|c|c|}
\hline \multirow[b]{2}{*}{ Mês } & \multicolumn{2}{|c|}{ Shannon } & \multicolumn{2}{|c|}{$\mathrm{CDC}$} & \multicolumn{2}{|c|}{ Total } \\
\hline & Machos & Fêmeas & Machos & Fêmeas & Machos & Fêmeas \\
\hline Mai/99 & 30 & 52 & 15 & 19 & 45 & 70 \\
\hline Jun/99 & 4 & 19 & 0 & 0 & 4 & 19 \\
\hline Jul/99 & 18 & 33 & 15 & 24 & 33 & 57 \\
\hline Ago/99 & 203 & 317 & 78 & 117 & 281 & 434 \\
\hline Set/99 & 83 & 141 & 22 & 34 & 105 & 175 \\
\hline Out/99 & 9 & 50 & 72 & 117 & 81 & 167 \\
\hline Nov/99 & 541 & 1.926 & 103 & 393 & 644 & 2.289 \\
\hline Dez/99 & 21 & 43 & 5 & 17 & 26 & 60 \\
\hline $\mathrm{Jan} / 00$ & 12 & 36 & 2 & 12 & 14 & 48 \\
\hline Fev/00 & 138 & 209 & 6 & 17 & 144 & 236 \\
\hline $\mathrm{Mar} / 00$ & 28 & 78 & 5 & 12 & 33 & 90 \\
\hline $\mathrm{Abr} / 00$ & 139 & 132 & 55 & 36 & 194 & 168 \\
\hline Total & 1.226 & 3.036 & 378 & 797 & 1.604 & 3.833 \\
\hline
\end{tabular}




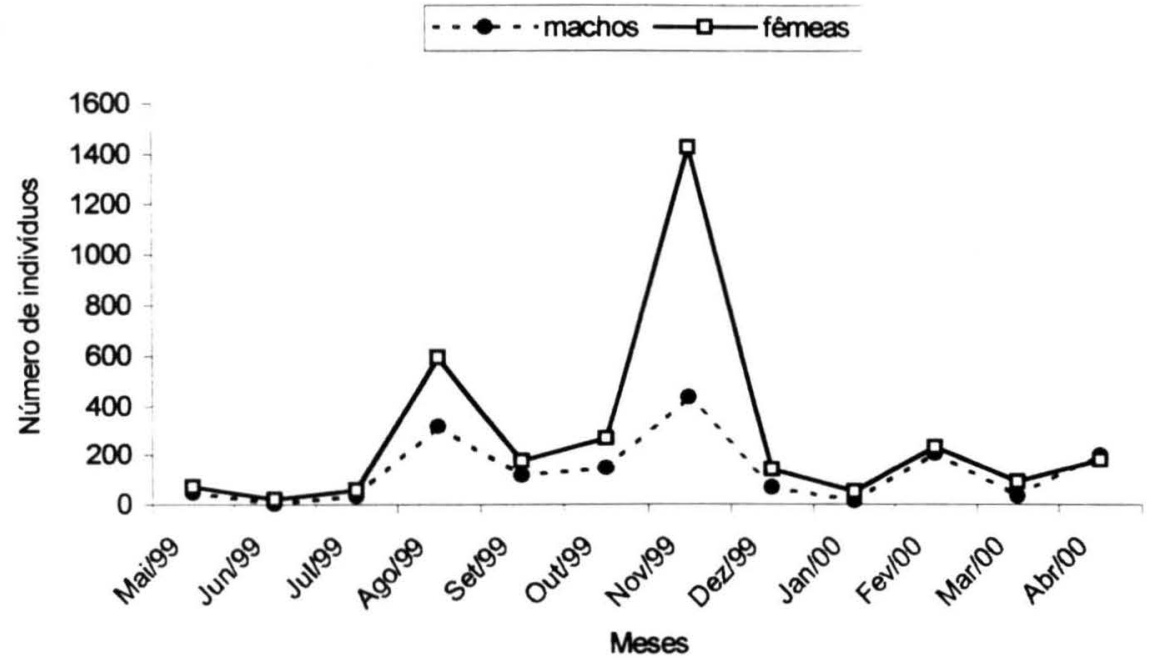

Figura 3. Distribuição mensal do número total de machos e fềmeas de $L$. intermedia s.l. coletados em armadilhas de Shannon e CDC, na zona rural do município de Conchal, no período de maio de 1999 a abril de 2000.

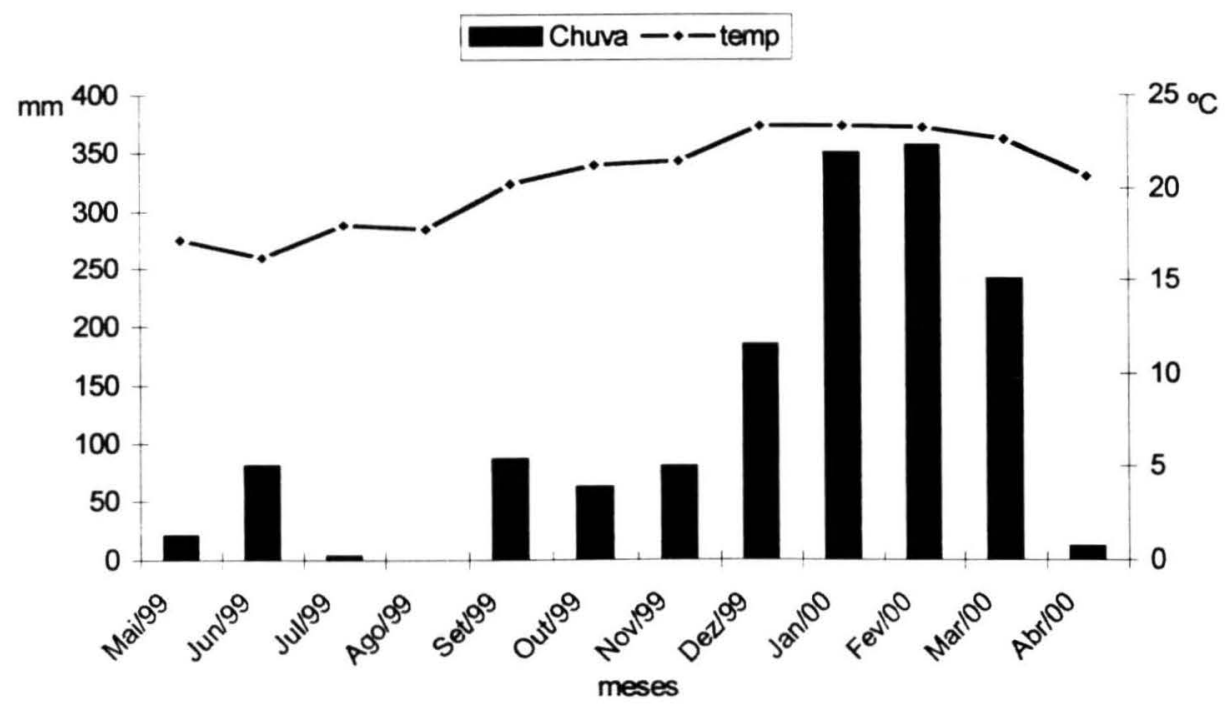

Figura 4. Distribuição mensal da chuva e das médias das temperaturas, no período de maio de 1999 e abril de 2000 (Fonte: Instituto Florestal - Estação Experimental de Mogi Guaçu-SP). 
Pelas coletas realizadas com armadilhas $\mathrm{CDC}$, pode-se observar que tanto os machos como as fêmeas de L. intermedia s.l. ocorreram em todos os ambientes pesquisados (tabela 3). No entanto, existe uma diferença significativa na distribuição dos flebotomíneos por estes ambientes $\left(X^{2}=297\right.$ e 786, para machos e fêmeas, respectivamente, $\mathrm{gl}=5, \mathrm{p}<0,001)$. A maior abundância ocorreu no ambiente de mata ao nível do solo, com $580(49,4 \%)$ do total de indivíduos coletados. Considerando-se somente as fềmeas, as maiores abundâncias ocorreram na mata ao nível do solo $(51,1$ $\%$, no peridomicílio $(17,7 \%)$ e na varanda dos domicilios $(15,4 \%)$ (tabela 3$)$. A abundância dos machos entre os ambientes, acompanhou as mesmas tendências das fềmeas (tabela 3).

Tabela 3. Distribuição ambiental de machos e fềmeas de L. intermedia s.l. coletados em armadilhas CDC, na zona rural do município de Conchal, no período de maio de 1999 a abril de 2000 .

\begin{tabular}{lcccccc}
\hline Ambiente & \multicolumn{2}{c}{ Machos } & \multicolumn{2}{c}{ Fêmeas } & \multicolumn{2}{c}{ Total } \\
\cline { 2 - 7 } & $\mathrm{N}$ & $\%$ & $\mathrm{~N}$ & $\%$ & $\mathrm{~N}$ & $\%$ \\
\hline Mata copa & 3 & 0,8 & 3 & 0,4 & 6 & 0,5 \\
Mata solo & 173 & 45,8 & 407 & 51,1 & 580 & 49,4 \\
Margem. Mata & 38 & 10,0 & 94 & 11,8 & 132 & 11,2 \\
Aberto & 23 & 6,1 & 29 & 3,6 & 52 & 4,4 \\
Peridomicilio & 89 & 23,5 & 141 & 17,7 & 230 & 19,6 \\
Peri - Varanda & 52 & 13,8 & 123 & 15,4 & 175 & 14,9 \\
\hline Total & 378 & 100 & 797 & 100 & 1.175 & 100,0 \\
\hline
\end{tabular}




\subsection{Dispersão ambiental e parâmetros populacionais}

\subsubsection{Teste laboratorial de sobrevivência}

A mortalidade entre os grupos de flebotomíneos machos e fềmeas coletados no campo, marcados e não marcados (controle), não apresentou diferença significativa nos testes realizados em laboratório (figura 5).

Em abril e maio de 1999, quando foram realizados os testes de sobrevivência, a temperatura ambiente no laboratório variou de $17^{\circ} \mathrm{C}$ a $26^{\circ} \mathrm{C}$. Os dados, não transformados, forneceram retas significativamente diferentes de zero (ANOVA, $\mathbf{p}<0,05$ ), e os coeficientes de regressão, com exceção do teste realizado com fềmeas em maio, não diferiram significativamente na análise de covariância $(p>0,05)$. Em maio, as fềmeas marcadas sobreviveram significativamente mais do que as não marcadas $\left(A N C O V A<F_{1 ; 18}=6,243, p=0,021\right.$ ) (figura 5). Estes resultados demonstram que a marcação feita com pó fluorescente indicou não interferir na sobrevivência dos flebotomíneos, o que pode ser extrapolado para as condições de campo.

Ao final do décimo dia, apesar de ainda existirem indivíduos vivos, deu-se por encerrado o experimento. Todos os machos e fêmeas marcados mantiveram a marca com o pó fluorescente até o encerramento do experimento.

A expectativa mediana de vida para os grupos marcados e não marcados foi de 9 e 8 dias, para machos, e 8 e 9 dias, para fêmeas, respectivamente, no teste realizado em abril. No teste realizado em maio, esses valores foram de 7 e 6 dias para os machos, e de 9 e 8 dias para fềmeas, marcados e não marcados, respectivamente. 

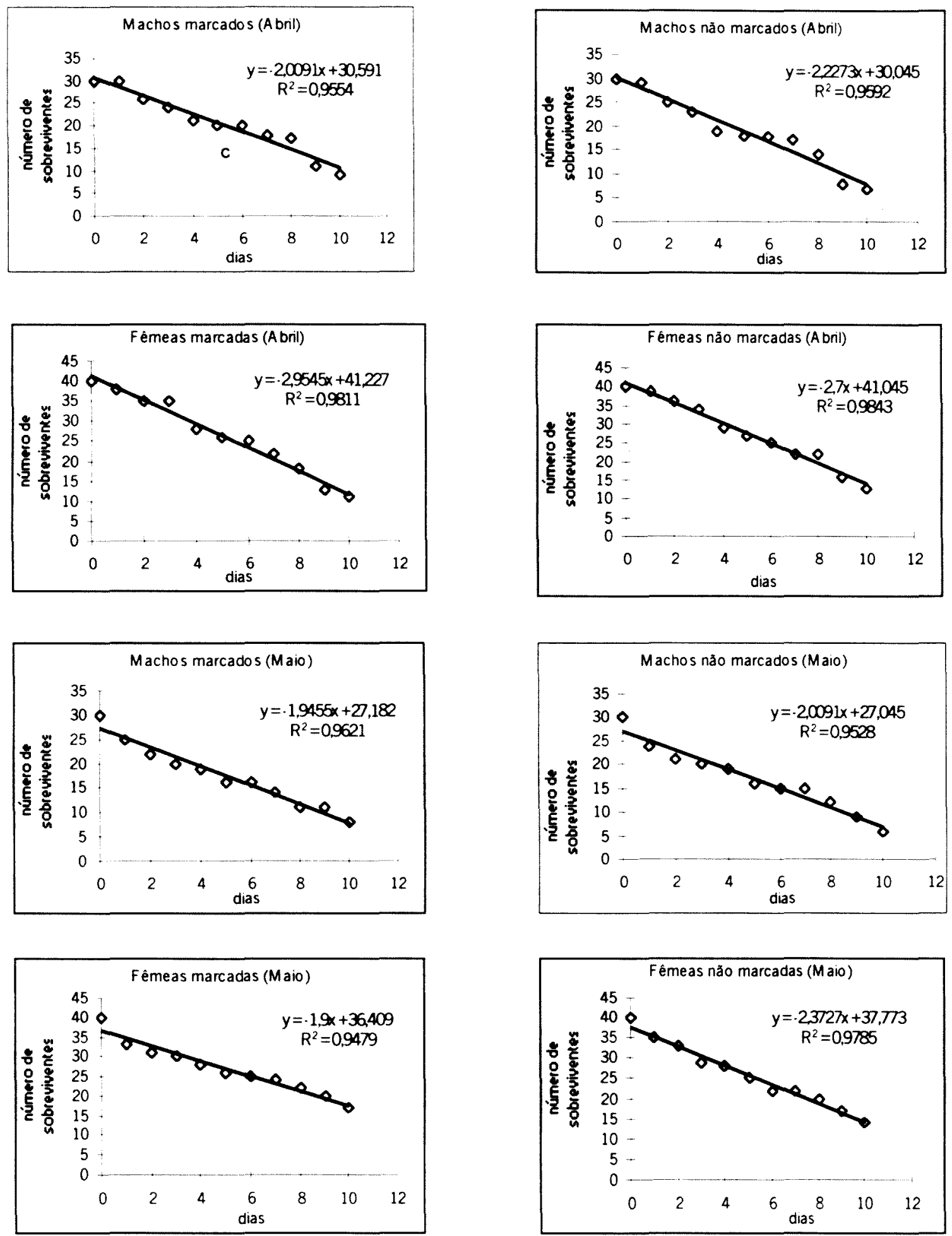

Figura 5. Curvas de sobrevivência, de machos e fềmeas de L. intermedia s.l., marcados e não marcados, obtidas em condição de laboratório nos meses de abril e maio de 1999. 


\subsubsection{Sucesso de recaptura}

Durante os meses de agosto a novembro de 1999, e fevereiro e abril de 2000, foram marcados e soltos 2.014 machos e 4.488 fềmeas de flebotomíneos na área de estudo (tabela 4). O número de machos e fềmeas dos indivíduos marcados e soltos foi extrapolado da proporção sexual obtida em armadilha de Shannon, no $1^{\circ}$ dia de coleta após a soltura. Somente no mês de Novembro de 1999 foi utilizada a proporção do $2^{\circ}$ dia de coleta, devido ao baixo número coletado no primeiro dia.

Foram recapturados 188 machos e 305 fêmeas, correspondentes a taxas de recaptura de $9,3 \%$ e $6,8 \%$, respectivamente (tabela 4). Todos os flebotomíneos eram pertencentes a $L$. intermedia s.l. Este fato, somado à predominância quase que absoluta de L. intermedia s.l. nas coletas totais de flebotomineos (tabela 1) permite assumir, com pequena margem de erro, que os flebotomíneos marcados e soltos pertenciam a $L$. intermedia s.l. Um maior número de machos (159) e de fềmeas (248) de L.intermedia foi recapturado nas armadilhas de Shannon, representando um total de $84,6 \%$ e $80,6 \%$ do total de cada sexo recapturado, respectivamente. Nas armadilhas de Shannon, a taxa de recaptura de machos de L. intermedia s.l. (7,9\%), foi significativamente maior $\left(\mathrm{X}^{2}=11,9 ; \mathrm{gl}=1 ; \mathrm{p}<0,005\right)$ do que a taxa de recaptura de fềmeas $(5,5 \%)$. Nas armadilhas $\mathrm{CDC}$, as taxas de recaptura de machos e fêmeas foram praticamente idênticas (tabela 4). 
Tabela 4. Número de machos e fềmeas de L. intermedia s.l. soltos e recapturados em armadilhas de Shannon e CDC, na zona rural do município de Conchal, no período de agosto de 1999 a abril de 2000 ,

\begin{tabular}{|c|c|c|c|c|c|c|c|c|}
\hline \multirow[b]{2}{*}{ Mês } & \multicolumn{2}{|c|}{$\mathrm{N}^{\circ}$ soltos } & \multicolumn{2}{|c|}{$\begin{array}{l}\mathrm{N}^{\mathrm{o}}(\%) \\
\text { recapturados } \\
\text { Shannon }\end{array}$} & \multicolumn{2}{|c|}{$\begin{array}{c}\mathrm{N}^{\circ}(\%) \\
\text { recapturados } \\
\mathrm{CDC}\end{array}$} & \multicolumn{2}{|c|}{ TOTAL } \\
\hline & $\mathrm{M}$ & $\mathrm{F}$ & $M$ & $\mathrm{~F}$ & $\mathrm{M}$ & $F$ & $\mathrm{M}$ & $F$ \\
\hline *Ago & 141 & 533 & $\begin{array}{c}21 \\
(13,9)\end{array}$ & $\begin{array}{c}25 \\
(4,7)\end{array}$ & $\begin{array}{c}7 \\
(5,0)\end{array}$ & $\begin{array}{c}4 \\
(0,8)\end{array}$ & $\begin{array}{c}28 \\
(19,9)\end{array}$ & $\begin{array}{c}29 \\
(5,4)\end{array}$ \\
\hline Ago & 463 & 723 & $\begin{array}{c}55 \\
(11,9)\end{array}$ & $\begin{array}{c}83 \\
(11,5)\end{array}$ & $\begin{array}{c}0 \\
(0,0)\end{array}$ & $\begin{array}{c}2 \\
(0,3)\end{array}$ & $\begin{array}{c}55 \\
(11,9)\end{array}$ & $\begin{array}{c}85 \\
(11,8)\end{array}$ \\
\hline Set & 124 & 396 & $\begin{array}{c}10 \\
(8,1)\end{array}$ & $\begin{array}{c}26 \\
(6,6)\end{array}$ & $\begin{array}{c}4 \\
(3,2)\end{array}$ & $\begin{array}{c}0 \\
(0,0)\end{array}$ & $\begin{array}{c}14 \\
(11,3)\end{array}$ & $\begin{array}{c}26 \\
(6,6)\end{array}$ \\
\hline Out & 369 & 750 & $\begin{array}{c}12 \\
(3,3)\end{array}$ & $\begin{array}{c}28 \\
(3,7)\end{array}$ & $\begin{array}{c}3 \\
(0,8)\end{array}$ & $\begin{array}{c}3 \\
(0,4)\end{array}$ & $\begin{array}{c}15 \\
(4,1)\end{array}$ & $\begin{array}{c}31 \\
(4,1)\end{array}$ \\
\hline Nov & 354 & 1.131 & $\begin{array}{c}32 \\
(9,0)\end{array}$ & $\begin{array}{c}66 \\
(6,8)\end{array}$ & $\begin{array}{c}14 \\
(4,0)\end{array}$ & $\begin{array}{c}45 \\
(4,5)\end{array}$ & $\begin{array}{c}46 \\
(13,0)\end{array}$ & $\begin{array}{c}111 \\
(11,3)\end{array}$ \\
\hline Fev & 325 & 295 & $\begin{array}{c}18 \\
(5,5)\end{array}$ & $\begin{array}{c}11 \\
(4,4)\end{array}$ & $\begin{array}{c}0 \\
(0,0)\end{array}$ & $\begin{array}{c}1 \\
(0,3)\end{array}$ & $\begin{array}{c}18 \\
(5,5)\end{array}$ & $\begin{array}{c}14 \\
(4,7)\end{array}$ \\
\hline Abr & 238 & 262 & $\begin{array}{c}11 \\
(4,6)\end{array}$ & $\begin{array}{c}9 \\
(3,4)\end{array}$ & $\begin{array}{c}1 \\
(0,4)\end{array}$ & $\begin{array}{c}2 \\
(0,8)\end{array}$ & $\begin{array}{c}12 \\
(5,0)\end{array}$ & $\begin{array}{c}11 \\
(4,2)\end{array}$ \\
\hline Total & 2.014 & 4.488 & $\begin{array}{c}159 \\
(7,9)\end{array}$ & $\begin{array}{c}248 \\
(5,5)\end{array}$ & $\begin{array}{c}29 \\
(1,4)\end{array}$ & $\begin{array}{c}57 \\
(1,3)\end{array}$ & $\begin{array}{c}188 \\
(9,3)\end{array}$ & $\begin{array}{c}305 \\
(6,8)\end{array}$ \\
\hline
\end{tabular}

* No mês de agosto foram realizados 2 experimentos

\subsubsection{Dispersão ambiental}

A utilização de um maior número de armadilhas $\mathrm{CDC}$, em relação ao de armadilhas de Shannon, permitiu a amostragem de um maior número de distâncias a partir do ponto de soltura. Assim, as análises referentes à amplitude máxima de 
dispersão, média aritmética e mediana da distância de dispersão dos indivíduos machos e fêmeas de L. intermedia s.l. foram baseadas nas recapturas realizadas com armadilhas CDC (figura 1).

O número total de machos (29) e de fềmeas (57) recapturados em armadilhas CDC não decresce como uma função linear da distância das armadilhas a partir do ponto de soltura (para machos: $\ln (\mathrm{Y}+1)=-0,001 \mathrm{x}+1,122 ; \mathrm{p}>0,75 ; \mathrm{r}^{2}=0,01 ;$ para fêmeas: $\ln (Y+1)=-0,003 x+1,414 ; p>0,55 ; r^{2}=0,160$ ) (figura 6).
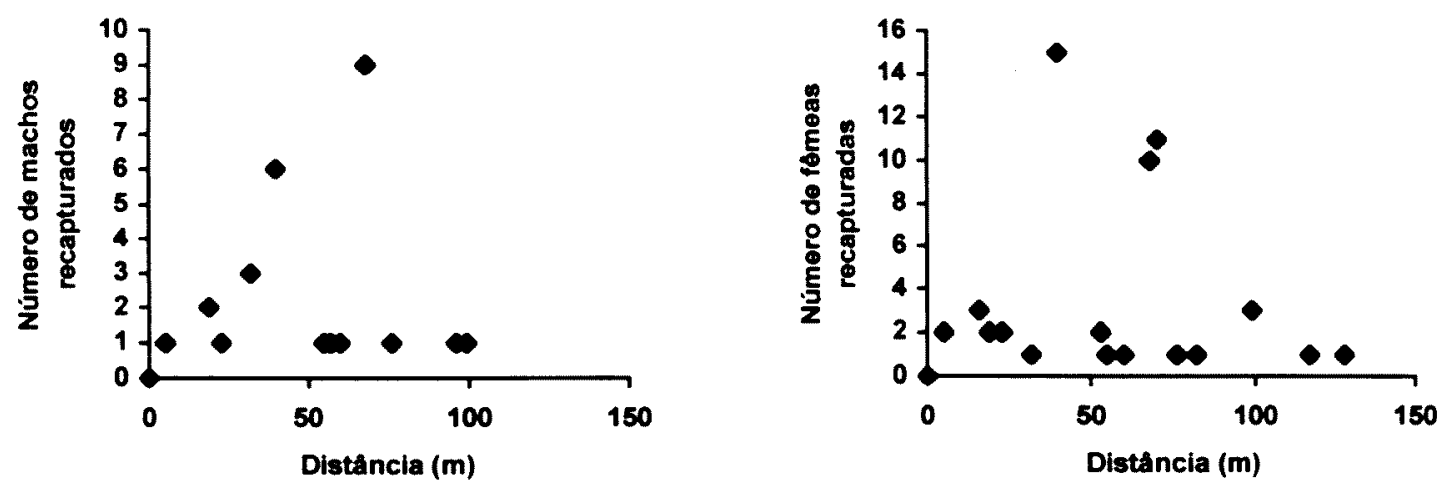

Figura 6. Relação entre o número total de machos e fềmeas de L. intermedia s.l. recapturado e a distância das armadilhas CDC a partir do ponto de soltura, na zona rural do município de Conchal, no período de agosto de 1999 a abril de 2000.

A distribuição de freqüência, apresentada na figura 6, permitiu estimar a média aritmética da distância de dispersão, que foi de $53 \mathrm{~m}$ para os machos e de $55 \mathrm{~m}$ para as fềmeas. A mediana de dispersão, por sua vez, foi de foi de $56 \mathrm{~m}$ para os machos, sendo que $86 \%$ foram coletados até $68 \mathrm{~m}$ do ponto de soltura. Para as fêmeas, a mediana foi de $55 \mathrm{~m}$ e $89 \%$ delas foram coletadas até $70 \mathrm{~m}$ do ponto de soltura. 
A amplitude máxima de dispersão para machos e fềmeas de L. intermedia s.l. foi de 99 e $128 \mathrm{~m}$, respectivamente, relativos a um único exemplar para cada sexo. O macho foi coletado no ambiente de mata e a fềmea no peridomicilio, a 7 e 8 dias após a soltura, respectivamente, realizada na margem da mata.

$\mathrm{O}$ maior número de indivíduos recapturados nas armadilhas $\mathrm{CDC}$ no mês de novembro de 1999 possibilitou a estimativa da distância média de dispersão diária. Esta foi calculada pelo número de machos e fềmeas de $L$. intermedia s.l. recapturados em 16 armadilhas CDC, ajustado para o tamanho da área amostrada, segundo o método de BRENNER e col. (1984) (tabela 5).

Tabela 5. Distância média de dispersão diária e número total e corrigido de machos e fềmeas de $L$. intermedia s.l. recapturados em 4 dias de coleta em CDC, na zona rural do município de Conchal, no mês de novembro de 1999. (FC = Fator de Correção).

\begin{tabular}{|c|c|c|c|c|c|c|c|c|c|c|c|c|c|c|c|c|c|}
\hline \multirow{3}{*}{$\begin{array}{l}\text { Raio do } \\
\text { círculo } \\
\text { (m) }\end{array}$} & \multirow{3}{*}{ F C } & \multicolumn{8}{|c|}{ Número Recapturado } & \multicolumn{8}{|c|}{ Número Corrigido } \\
\hline & & \multicolumn{2}{|c|}{$2^{\circ} \mathrm{dia}$} & \multicolumn{2}{|c|}{$3^{\circ} \mathrm{dia}$} & \multicolumn{2}{|c|}{$4^{\circ} \mathrm{dia}$} & \multicolumn{2}{|c|}{$7^{\circ} \mathrm{dia}$} & \multicolumn{2}{|c|}{$2^{\circ} \mathrm{dia}$} & \multicolumn{2}{|c|}{$3^{\circ} \mathrm{dia}$} & \multicolumn{2}{|c|}{$4^{\circ} \mathrm{dia}$} & \multicolumn{2}{|c|}{$7^{\circ} \mathrm{dia}$} \\
\hline & & $\mathrm{M}$ & $\mathrm{F}$ & $\mathrm{M}$ & $\mathrm{F}$ & $\mathrm{M}$ & $F$ & $M$ & $F$ & $M$ & $\mathrm{~F}$ & $\mathrm{M}$ & $\mathrm{F}$ & $M$ & $F$ & $\mathrm{M}$ & $F$ \\
\hline $0-40$ & 1,0 & 3 & 8 & 2 & 5 & 1 & 1 & 1 & 1 & 3 & 8 & 2 & 5 & 1 & 1 & 1 & 1 \\
\hline $40-80$ & 3,0 & 3 & 13 & 1 & 7 & 2 & 8 & 1 & 2 & 9 & 39 & 3 & 21 & 6 & 24 & 3 & 6 \\
\hline $80-120$ & 5,0 & 0 & 0 & 0 & 0 & 0 & 0 & 0 & 0 & 0 & 0 & 0 & 0 & 0 & 0 & 0 & 0 \\
\hline $120-160$ & 7,0 & 0 & 0 & 0 & 0 & 0 & 0 & 0 & 0 & 0 & 0 & 0 & 0 & 0 & 0 & 0 & 0 \\
\hline Total & & 6 & 21 & 3 & 12 & 3 & 9 & 2 & 3 & 12 & 47 & 5 & 26 & 7 & 25 & 4 & 7 \\
\hline Distânci & édiz & D & oers & D & & & & & & 50 & 53 & 44 & 52 & 29 & 58 & 50 & 54 \\
\hline
\end{tabular}

Pode-se observar que a distância média de dispersão, a partir do ponto central de soltura na margem da mata, manteve-se praticamente constante para as fêmeas entre o segundo e sétimo dia após a soltura, Para os machos, ocorreu uma ligeira 
queda na distância média entre o segundo e quarto dia (figura 7). Esses dados mostram a baixa tendência de dispersão de L. intermedia s.l.

Considerando todos os experimentos, o intervalo de tempo mais longo, a partir da noite de soltura, em que foram recapturados flebotomíneos, foi de 11 dias para 2 fềmeas e de 14 dias para 2 machos, coletados a menos de $80 \mathrm{~m}$ do ponto de soltura.
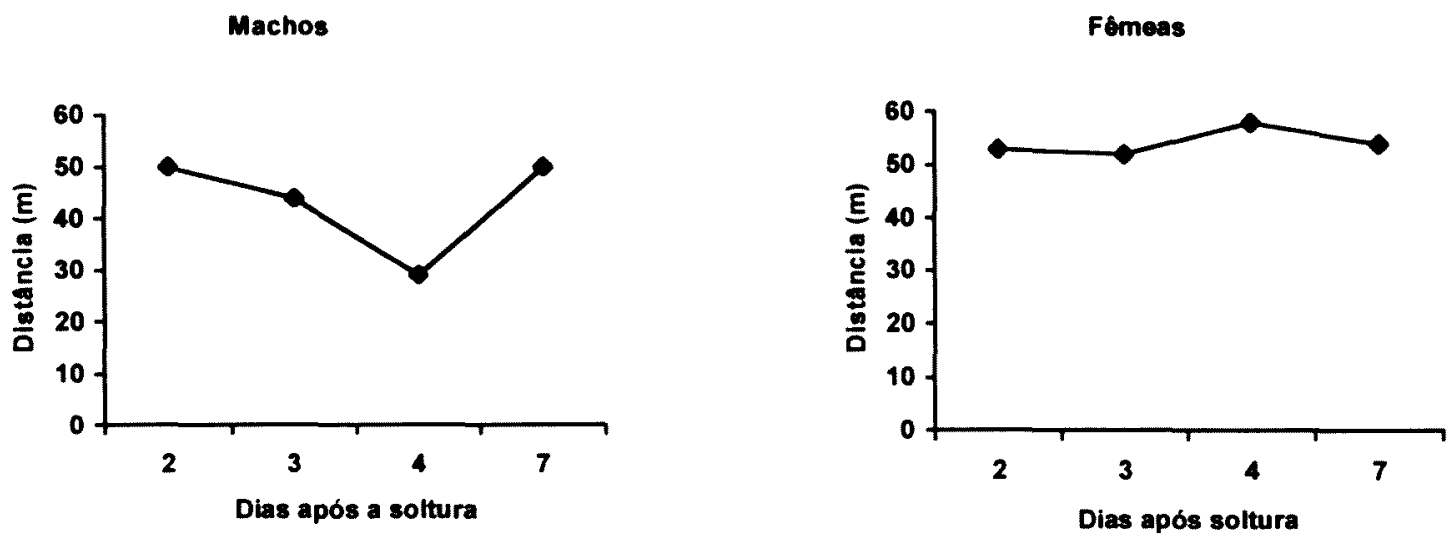

Figura 7. Distância média de dispersão diária, a partir do ponto de soltura, para 4 dias de recaptura com armadilhas CDC, na zona rural do município de Conchal, no mês de novembro de 1999.

As recapturas mensais de exemplares de L. intermedia s.l. em armadilhas de Shannon foram utilizadas para verificar a direção da dispersão para os ambientes de mata, margem mata e peridomiciliar, a partir do ponto central de soltura situado na margem da mata (figura 8). Em maior número de ocasiões, 3 vezes para as fềmeas e 3 para os machos, ocorreu uma diferença significativa de dispersão em direção às armadilhas situadas no interior da mata. 


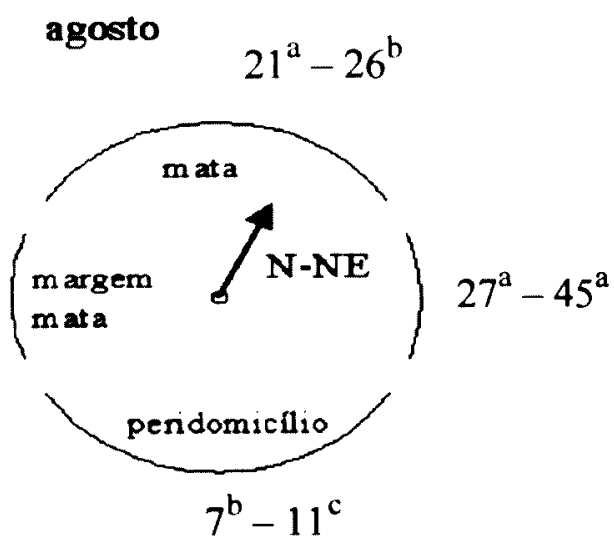

outubro
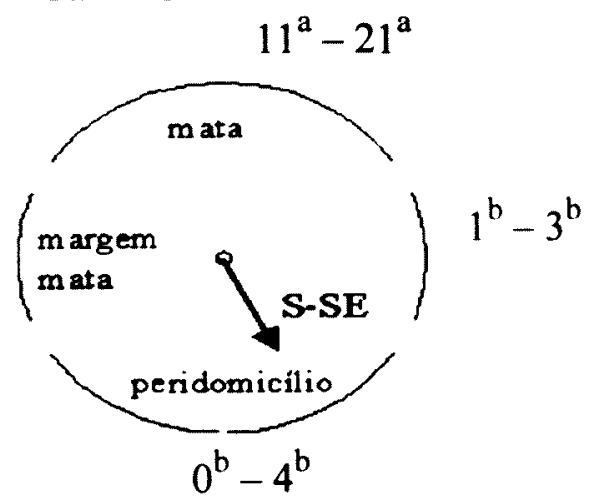

fevereiro

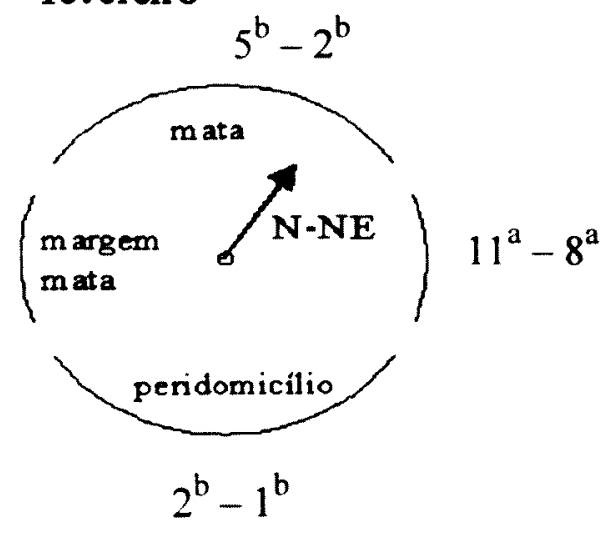

setembro

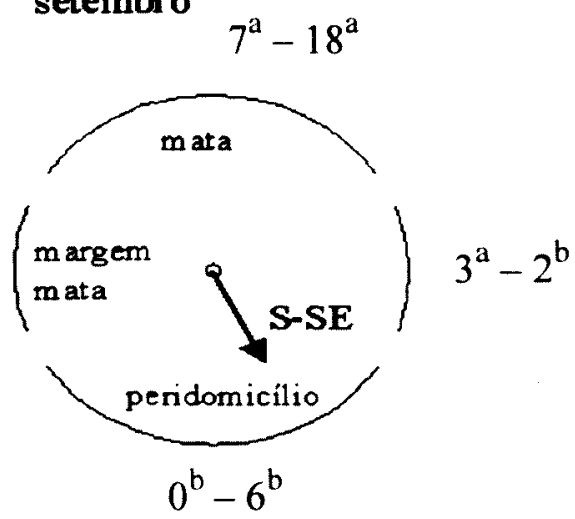

novembro

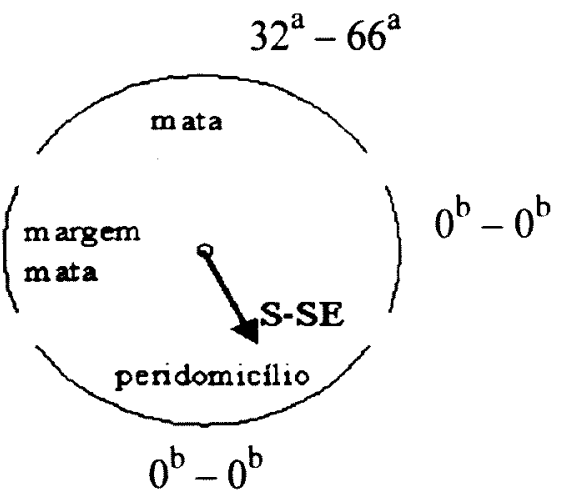

abril

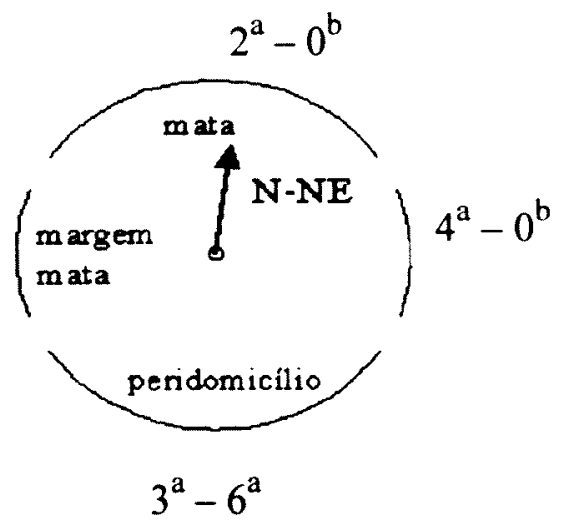

Figura 8. Número de machos - fềmeas de L. intermedia s.l., recapturados em armadilhas de Shannon situadas na mata, margem da mata e peridomicilio, na zona rural do município de Conchal, no período de agosto de 1999 a abril de 2000. O centro do círculo representa o ponto de soltura. A seta representa a direção predominante do vento durante os períodos de coleta. Letras diferentes mostram diferenças significativas intrasexo no teste de qui-quadrado $(p<0,05)$. 
O ambiente de margem da mata foi o segundo em tendência de direção de dispersão dos flebotomíneos. Em somente uma ocasião, no mês de abril de 2000, as fềmeas de L. intermedia s.l. dispersaram em direção ao ambiente peridomiciliar. A direção predominante do vento entre os dias e horários de coleta não pareceu influenciar na direção de dispersão dos flebotomíneos (figura 8).

\subsubsection{Sobrevivência}

As coletas de machos e fềmeas de L. intermedia s.l., em armadilhas de Shannon nos meses de agosto ( $2^{\circ}$ experimento) a novembro de 1999 e fevereiro e abril de 2000 foram suficientes (tabelas 6 e 7) para permitir as estimativas de sobrevivência, tamanho da população e taxa de adição. Por outro lado, o baixo valor do número de indivíduos recapturados nas armadilhas $\mathrm{CDC}$, com exceção de novembro de 1999 (tabela 4), não permitiram a utilização dos mesmos nas estimativas dos parâmetros populacionais. O grande número de exemplares marcados presentes nas coletas realizadas com armadilhas CDC, no mês de novembro de 1999 (tabela 4), foi incorporado ao número recapturado nas armadilhas de Shannon, para a estimativa da sobrevivência neste mês.

As chuvas impediram a realização de coletas no primeiro dia após a soltura, no mês de setembro, no quarto dia de outubro e no sexto dia de novembro. Foram excluídas das análises as coletas nas quais ocorreram quedas bruscas no número de exemplares coletados. As quedas no número de indivíduos estiveram associadas à ocorrência de ventos fortes durante as coletas. 
Tabela 6. Número diário de machos e fềmeas de L. intermedia s.l. não marcados e recapturados, coletados em armadilha de Shannon, na zona rural do município de Conchal, nos meses de agosto a outubro de 1999.

\begin{tabular}{|c|c|c|c|c|c|c|c|c|c|c|c|c|}
\hline \multirow[t]{4}{*}{ Noite } & \multicolumn{4}{|c|}{ Agosto } & \multicolumn{4}{|c|}{ Setembro } & \multicolumn{4}{|c|}{ Outubro } \\
\hline & \multicolumn{2}{|c|}{ Não } & \multirow{2}{*}{\multicolumn{2}{|c|}{ Recapturado }} & \multicolumn{2}{|c|}{ Não } & \multicolumn{6}{|c|}{ Não } \\
\hline & \multicolumn{2}{|c|}{ marcado } & & & \multicolumn{2}{|c|}{ marcado } & \multicolumn{2}{|c|}{ Recapturado } & \multicolumn{2}{|c|}{ marcado } & \multicolumn{2}{|c|}{ Recapturado } \\
\hline & $\mathrm{M}$ & $\mathrm{F}$ & $\bar{M}$ & $\mathrm{~F}$ & $\mathrm{M}$ & $\mathrm{F}$ & $\mathbf{M}$ & $F$ & $\mathrm{M}$ & $\mathrm{F}$ & $M$ & $\mathrm{~F}$ \\
\hline 1 & 203 & 317 & 27 & 39 & - & - & - & - & 164 & 333 & 8 & 17 \\
\hline 2 & 162 & 618 & 9 & 16 & 140 & 224 & 6 & 16 & 52 & 81 & 2 & 6 \\
\hline 3 & 378 & 453 & 4 & 7 & 71 & 154 & 2 & 4 & $* 29$ & $* 38$ & 0 & 0 \\
\hline 4 & 284 & 602 & 6 & 7 & 89 & 146 & 1 & 3 & - & - & - & - \\
\hline 5 & 237 & 439 & 5 & 7 & $* 7$ & $* 31$ & 0 & 0 & 71 & 133 & 2 & 4 \\
\hline 6 & 214 & 392 & 2 & 3 & 83 & 141 & 1 & 3 & $* 13$ & $* 12$ & 0 & 0 \\
\hline 7 & 203 & 924 & 2 & 4 & 81 & 46 & 0 & 0 & 9 & 50 & 0 & 1 \\
\hline 8 & - & - & - & - & - & - & - & - & $* 0$ & $* 3$ & 0 & 0 \\
\hline Total & 1.681 & 3.745 & 55 & 83 & 471 & 742 & 10 & 26 & 338 & 650 & 12 & 28 \\
\hline
\end{tabular}


Tabela 7. Número diário de machos e fêmeas de $L$. intermedia s.l. não marcados e recapturados, coletados em armadilha de Shannon, na zona rural do município de Conchal, nos meses de novembro de 1999, fevereiro e abril de 2000.

\begin{tabular}{|c|c|c|c|c|c|c|c|c|c|c|c|c|}
\hline \multirow[t]{4}{*}{ Noite } & \multicolumn{4}{|c|}{ Novembro } & \multicolumn{4}{|c|}{ Fevereiro } & \multicolumn{4}{|c|}{ Abril } \\
\hline & \multicolumn{2}{|c|}{ Não } & \multirow{2}{*}{\multicolumn{2}{|c|}{ Recapturado }} & \multicolumn{2}{|c|}{ Não } & \multicolumn{6}{|c|}{ Não } \\
\hline & \multicolumn{2}{|c|}{ marcado } & & & \multicolumn{2}{|c|}{ marcado } & \multicolumn{2}{|c|}{ Recapturado } & \multicolumn{2}{|c|}{ marcado } & \multicolumn{2}{|c|}{ Recapturado } \\
\hline & $\mathrm{M}$ & $\mathrm{F}$ & $* * \mathrm{M}$ & $* * \mathrm{~F}$ & $M$ & $F$ & $M$ & $F$ & $\mathrm{M}$ & $\mathrm{F}$ & $\mathrm{M}$ & $\mathrm{F}$ \\
\hline 1 & $* 3$ & $* 10$ & 0 & 1 & 359 & 339 & 12 & 6 & 139 & 132 & 6 & 3 \\
\hline 2 & 106 & 339 & 17 & 45 & 243 & 209 & 5 & 4 & 217 & 175 & 2 & 2 \\
\hline 3 & 578 & 1.581 & 17 & 42 & * 14 & * 24 & 0 & 0 & 148 & 129 & 1 & 1 \\
\hline 4 & 541 & 1.926 & 10 & 19 & 138 & 209 & 1 & 1 & 62 & 132 & 0 & 0 \\
\hline 5 & ${ }^{*} 11$ & *157 & 0 & 1 & * 14 & $* 14$ & 0 & 0 & 212 & 203 & 0 & 0 \\
\hline 6 & - & - & - & - & 57 & 99 & 0 & 0 & - & - & - & - \\
\hline 7 & 97 & 283 & 2 & 3 & 113 & 201 & 0 & 0 & - & - & - & - \\
\hline Total & 1.336 & 4.296 & 46 & 111 & 938 & 1.095 & 18 & 11 & 778 & 771 & 9 & 6 \\
\hline
\end{tabular}

* excluídos da análise da curva de sobrevivência por apresentarem quedas bruscas na coleta de machos e fêmeas.

** incluídos os indivíduos recapturados nas armadilhas CDC

A sobrevivência diária foi estimada pela regressão do número de indivíduos de L. intermedia s.l. recapturados (tabelas 6 e 7$)$, transformados em $\ln (y+1)$, em função dos dias após a soltura. As figuras 9a e 9b apresentam as curvas de sobrevivência obtidas com essas regressões, para os machos e as fềmeas de $L$. intermedia s.l., nos meses de agosto a novembro de 1999 e fevereiro e abril de 2000. 

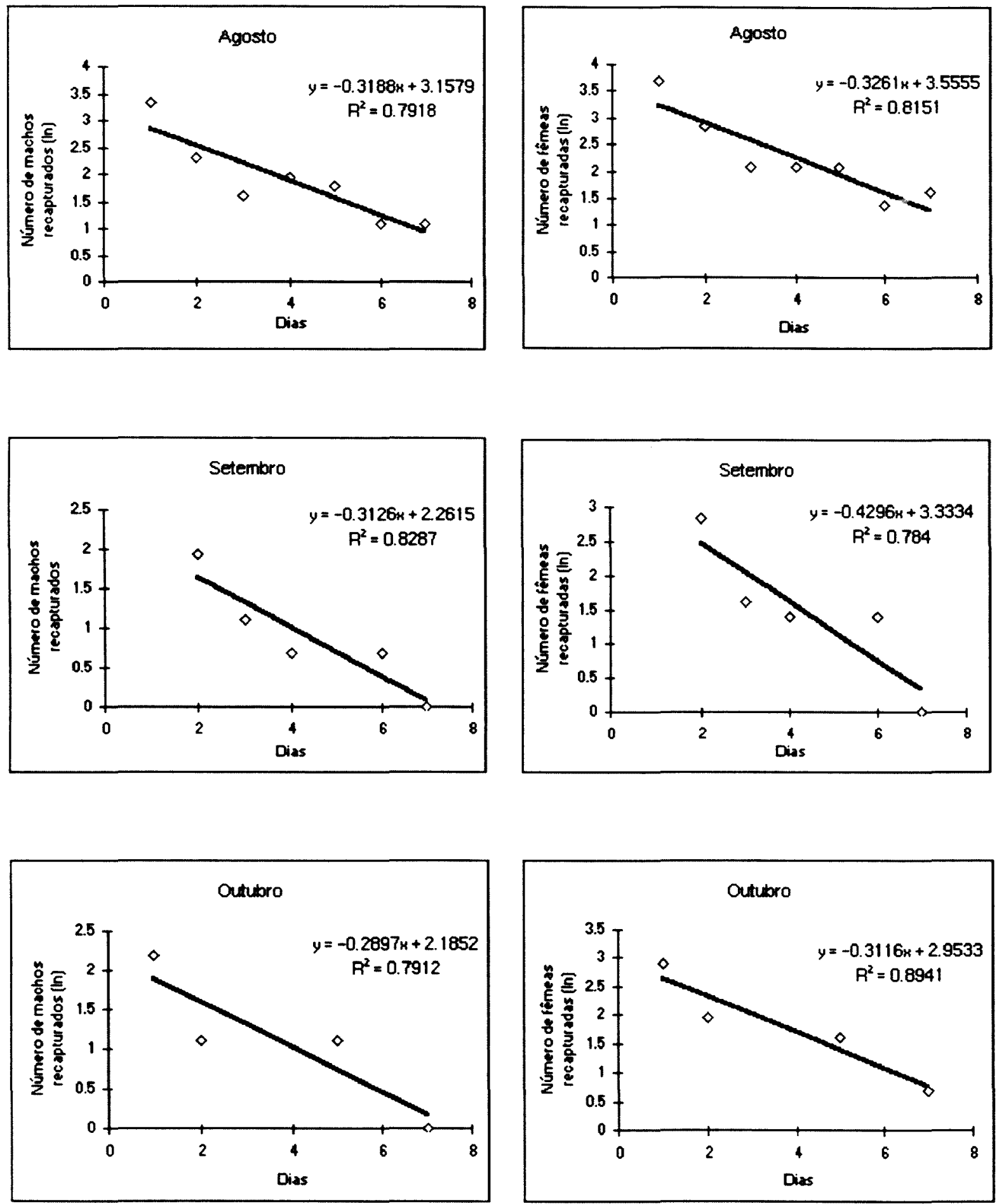

Figura 9a. Regressão do número de indivíduos $(\ln (\mathrm{y}+1))$ machos e fềmeas, de $L$. intermedia s.l. . recapturados em armadilhas de Shannon, e dos dias após a soltura, na zona rural do município de Conchal, nos meses de agosto a outubro de $1999 .\left(\mathrm{R}^{2}=\right.$ coeficiente de determinação). 

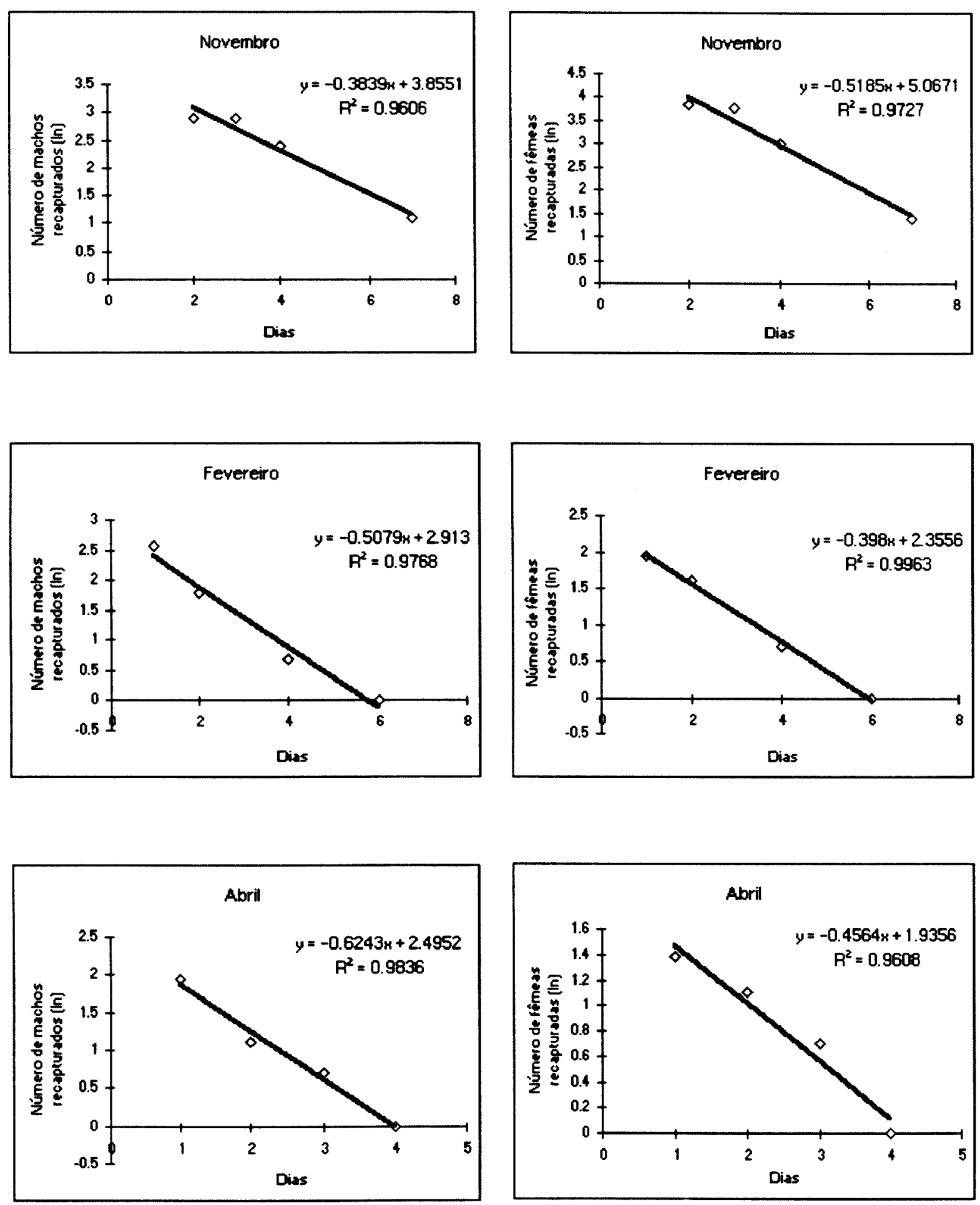

Figura 9b. Regressão do número de indivíduos $(\ln (\mathrm{y}+1))$ machos e fềmeas, de $L$. intermedia s.l., recapturados em armadilhas de Shannon, e dos dias após a soltura, na zona rural do município de Conchal, nos meses de novembro de 1999 e fevereiro e abril de 2000. ( $\mathrm{R}^{2}=$ coeficiente de determinação). 
A tabela 8 apresenta os valores das equações de regressão, bem como os das taxas de sobrevivência (s) obtidas pelo antilogaritmo do coeficiente de regressão (b). Inicialmente a sobrevivência foi estimada para cada mês separadamente. Cada coeficiente de regressão foi testado pela análise de variância e então comparados pela análise de covariância.

Tabela 8. Resumo das estimativas mensais da sobrevivência de indivíduos machos e fềmeas de L. intermedia s.l.. $\mathrm{b}=$ coeficiente de regressão; $\mathrm{R}^{2}=$ coeficiente de determinação; $p=$ grau de significância da reta; $s=$ sobrevivência.

\begin{tabular}{lcccccccc}
\hline & \multicolumn{9}{c}{ Machos } & \multicolumn{5}{c}{ Fêmeas } \\
\cline { 2 - 8 } Mês & $\mathrm{b}$ & $\mathrm{R}^{2}$ & $\mathrm{p}$ & $\mathrm{s}$ & $\mathrm{b}$ & $\mathrm{R}^{2}$ & $\mathrm{p}$ & $\mathrm{s}$ \\
\hline Ago/99 & $-0,319$ & 0,792 & 0,007 & 0,727 & $-0,326$ & 0,815 & 0,005 & 0,722 \\
Set/99 & $-0,313$ & 0,828 & 0,031 & 0,732 & $-0,430$ & 0,784 & 0,045 & 0,651 \\
Out/99 & $-0,290$ & 0,791 & $0,110^{*}$ & 0,749 & $-0,312$ & 0,894 & $0,054^{*}$ & 0,732 \\
Nov/99 & $-0,384$ & 0,961 & 0,019 & 0,681 & $-0,519$ & 0,973 & 0,013 & 0,595 \\
Fev/00 & $-0,508$ & 0,977 & 0,011 & 0,602 & $-0,388$ & 0,996 & 0,001 & 0,672 \\
Abr/00 & $-0,624$ & 0,984 & 0,008 & 0,536 & $-0,456$ & 0,961 & 0,019 & 0,634 \\
\hline * Não significativo pela ANOVA (p>0,05) & & & & & & \\
\hline
\end{tabular}

* Não significativo pela ANOVA $(p>0,05)$

Todos os coeficientes de regressão foram significativamente diferentes de zero, com exceção daqueles obtidos para os machos e fềmeas no mês de outubro (tabela 8). Não houve diferença significativa entre os coeficientes de regressão (ANCOVA, F $9,28=1,115, \mathrm{p}=0,358$ ), embora tenha sido observada diferença entre as médias ajustadas $(\mathrm{p}<0,05)$. Diferenças nas médias ajustadas podem ser esneradas 
uma vez que o número de individuos marcados e soltos e, posteriormente, recapturados variou entre os meses. Pode-se concluir que não houve diferença significativa entre as taxas de sobrevivência de machos e fềmeas em cada mês e nem entre os machos e entre as fêmeas nos diferentes meses de experimento. Portanto, optou-se por considerar o coeficiente de regressão comum a todas as regressões $(b=$ $-0,3941$ ), como representativo de todas as curvas de sobrevivência e, conseqüentemente, uma mesma taxa de sobrevivência $(s=0,6743)$ foi considerada, para machos e fềmeas em todos os meses.

\subsubsection{Tamanho da população e taxas de adição, perda e mudança}

O tamanho médio da população de $L$. intermedia s.l. variou, para os machos, de 928 exemplares, no mês de setembro de 1999, a 4.491, em fevereiro de 2000, e para as fềmeas, de 2.462 exemplares, no mês de setembro de 1999 , a 20.637 , em novembro de 1999 (tabelas 9a e 9b). Somente no mês de agosto, para os machos, e no mês de fevereiro, para as fềmeas, as taxas de perda da população (1sobrevivência) excederam as taxas de adição (calculada pela média da taxa de adição diária pelo método de MANLY e PARR 1968). No entanto, tanto estes valores negativos como os valores positivos encontrados para as taxas de mudança, sempre se apresentaram baixos, indicando que a população manteve-se praticamente constante durante os periodos dos experimentos em cada mês (tabelas 9a e 9b). 
Tabela 9a. Estimativas mensais do tamanho populacional (desvio padrão) e taxas de adição, perda e mudança de machos de L. intermedia s.l., na zona rural do município de Conchal, em agosto, setembro e novembro de 1999, e fevereiro e abril de 2000.

\begin{tabular}{|c|c|c|c|c|c|}
\hline \multirow[b]{2}{*}{ Mês } & \multicolumn{5}{|c|}{ Machos } \\
\hline & $\mathrm{TP}$ & (SD) & $\mathrm{Ta}$ & $\mathrm{Tp}$ & $\mathrm{Tm}$ \\
\hline Ago/99 & 3.739 & $(1.402)$ & 0,232 & 0,3257 & $-0,093$ \\
\hline Set/99 & 928 & $(488)$ & 0,383 & 0,3257 & 0,057 \\
\hline Nov/99 & 3.023 & $(1.076)$ & 0,364 & 0,3257 & 0,039 \\
\hline $\mathrm{Fev} / 00$ & 4.491 & $(1.869)$ & 0,148 & 0,3257 & 0,178 \\
\hline $\mathrm{Abr} / 00$ & 2.146 & (1.123) & 0,373 & 0,3257 & 0,045 \\
\hline
\end{tabular}

Tabela 9b. Estimativas mensais do tamanho populacional (desvios padrão) e taxas de adição, perda e mudança de fềmeas de $L$. intermedia s.l., na zona rural do município de Conchal, em agosto, setembro e novembro de 1999, e fevereiro e abril de 2000.

\begin{tabular}{lccccc}
\hline & \multicolumn{5}{c}{ Fêmeas } \\
\cline { 2 - 6 } Mês & TP & $(\mathrm{SD})$ & $\mathrm{Ta}$ & $\mathrm{Tp}$ & $\mathrm{Tm}$ \\
\hline Ago/99 & 7.955 & $(2453)$ & 0,390 & 03257 & 0,064 \\
Set/99 & 2.462 & $(1055)$ & 0,360 & 0,3257 & 0,034 \\
Nov/99 & 20.637 & $(7283)$ & 0,487 & 0,3257 & 0,161 \\
Fev/00 & 6.010 & $(2761)$ & 0,160 & 0,3257 & $-0,166$ \\
Abr/00 & 4.484 & $(2497)$ & 0,497 & 0,3257 & 0,171 \\
\hline $\begin{array}{l}\text { TP }=\text { tamanho populacional estimado, Ta }=\text { taxa de adição (Manly \& Parr, 1968), Tp = taxa de perda } \\
(1-\mathrm{s}), \text { Tm= taxa de mudança (Ta }- \text { Tp). }\end{array}$
\end{tabular}


A mudança sazonal no tamanho absoluto da população de fêmeas, estimado pelo método de Lincoln modificado (BAILEY 1952), esteve bem correlacionada com as mudanças sazonais relativas do número de fềmeas obtidas nas armadilhas de Shannon por mês de coleta $(\mathrm{r}=0,98 ; \mathrm{gl}=3, \mathrm{p}<0,005$ ) (figura 10). Os indivíduos machos não apresentaram a mesma correlação sazonal $(r=0,22, \mathrm{gl}=3, \mathrm{p}>0,50)$.

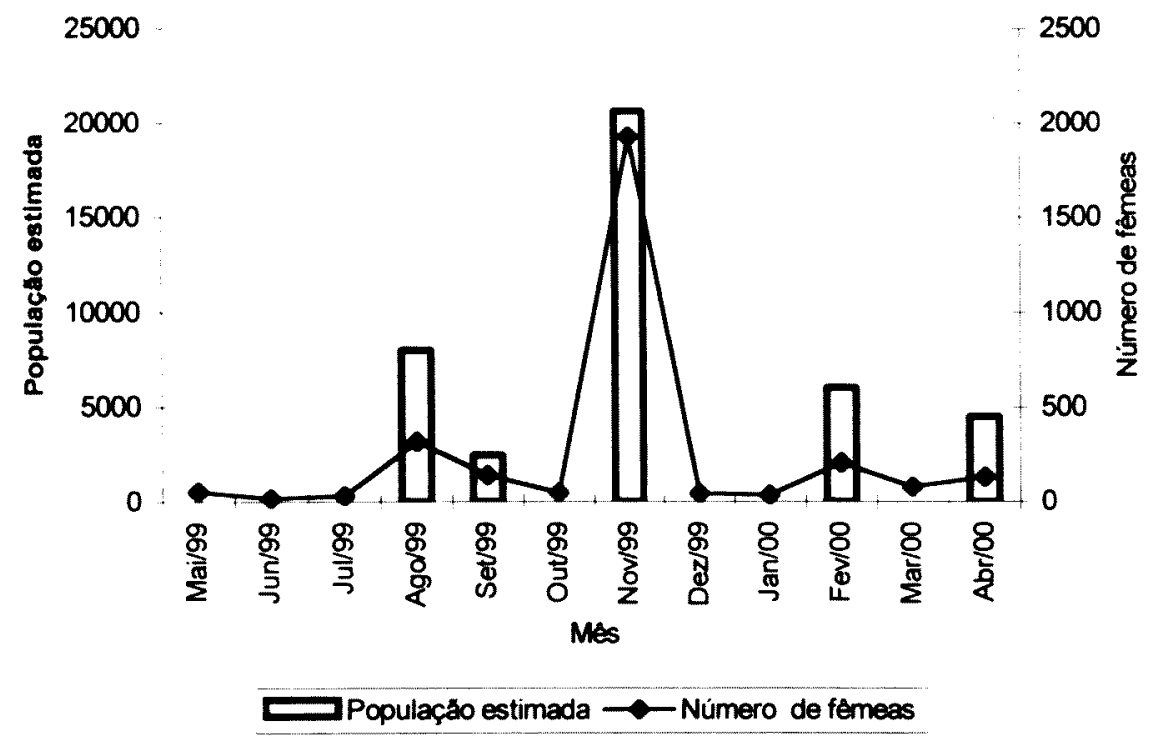

Figura 10. Relação entre a distribuição da população estimada pelo método modificado de BAILEY (1952) e a abundância relativa de fêmeas de L. intermedia s.l. coletadas em armadilhas de Shannon, na zona rural do município de Conchal, no período de maio de 1999 a abril de 2000.

A eficiência de amostragem das armadilhas de Shannon foi estimada dividindose o número médio de machos e fềmeas coletados por armadilha/noite, pela média absoluta do tamanho da população estimada por estas mesmas armadilhas. A porcentagem da população coletada por armadilha-noite variou, para machos, de 
$0,7 \%$ no mês de fevereiro de 2000 a $1,8 \%$ em novembro de 1999 e, para fềmeas, de $0,5 \%$ no mês de abril de 2000 a $1,0 \%$ em agosto e setembro de 1999 , e portanto, não podem servir como preditores do tamanho da população.

\subsubsection{Ciclo gonotrófico}

Nos meses de novembro de 1999 e fevereiro de 2000 foram marcadas e soltas 388 e 65 fềmeas ingurgitadas, respectivamente. A taxa de recaptura em novembro foi de $4,4 \%$ e em fevereiro de $3,1 \%$. Na tabela 10 , está apresentada a noite de soltura e as noites de recaptura, levando-se em conta o estado nutricional e fisiológico das fềmeas. Pode-se notar que na segunda noite após a alimentação, as fềmeas coletadas no experimento de novembro apresentavam-se com uma pequena quantidade de sangue no intestino, enquanto que a única fềmea coletada no experimento do mês de fevereiro já possuia ovos. Na terceira noite após a alimentação, todas as fêmeas recapturadas, nos dois meses de experimento, apresentavam-se com ovos maduros. As 5 fềmeas coletadas na quarta noite após a alimentação, do experimento de novembro, encontravam-se sem ovos e sangue. A duração do ciclo gonotrófico foi assumida como sendo o tempo entre a realização de um repasto sanguíneo e a oviposição. Assim, considerando que existe concordância gonotrófica, para as fêmeas de L. intermedia s.l., o seu ciclo se completou na terceira ou quarta noite após a alimentação. 
Tabela 10. Distribuição do número de fềmeas de L. intermedia s.l. recapturadas em noites seguidas após alimentação e soltura, na zona rural do município de Conchal, nos meses de novembro de 1999 e fevereiro de 2000.

\begin{tabular}{ccccccc}
\hline & \multicolumn{5}{c}{ Fêmeas recapturadas } \\
\cline { 2 - 7 } Noites após & Fêmeas & Fêmeas & Fêmeas & Fêmeas & Fêmeas & Fêmeas \\
alimentação & com & com ovos & vazias & com & com & vazias \\
e soltura & sangue & & & sangue & ovos & \\
\hline 2 & 6 & 0 & 0 & 0 & 1 & 0 \\
3 & 0 & 6 & 0 & 0 & 1 & 0 \\
4 & 0 & 0 & 5 & 0 & 0 & 0 \\
5 & 0 & 0 & 0 & 0 & 0 & 0 \\
6 & 0 & 0 & 0 & 0 & 0 & 0 \\
\hline Total & 6 & 6 & 5 & 0 & 2 & 0 \\
\hline
\end{tabular}

\subsection{Comportamento alimentar}

\subsubsection{Preferência alimentar}

De um total de 565 flebotomíneos capturados nas armadilhas iscadas e sem iscas, durante todos os experimentos, $99,8 \%$ eram $L$. intermedia s.l. Um maior número de exemplares de $L$. intermedia s.l. foi coletado no ambiente de mata $(76,3 \%)$, no entanto, a proporção de machos, em relação às fềmeas, foi significativamente maior nos dois ambientes investigados (Mata, $X^{2}=65,6, g l=1$, $\mathrm{p}<0,001 ;$ Peridomicílio, $\mathrm{X}^{2}=5,84 ; \mathrm{gl}=1 ; \mathrm{p}<0,01$ ) (tabela 11). Somente $20(6,7 \%)$ machos e $8(6,1 \%)$ fềmeas foram capturados na armadilha sem iscas (controle) no 
ambiente de mata. Nesta mesma armadilha, no ambiente peridomiciliar, números menores, $4(5,0 \%)$ machos e $1(1,9 \%)$ fêmea, foram coletados (tabela 11).

Tabela 11. Número total de machos e fêmeas de Lutzomyia intermedia coletadas em armadilhas tipo Disney, sem isca (controle) e com isca (cão, gambá, roedor), nos ambientes de mata e peridomiciliar, na zona rural do município de Conchal, no periodo de agosto/1999 a abril/2000.

\begin{tabular}{lcccccc}
\hline & \multicolumn{3}{c}{ Mata } & \multicolumn{3}{c}{ Peridomicílio } \\
\cline { 2 - 7 } Isca & Machos & Fêmeas & \% Fêmeas & Machos & Fêmeas & \% Fêmeas \\
\hline Cão & 119 & 66 & 35,7 & 43 & 33 & 43,4 \\
Gambá & 76 & 35 & 18,9 & 23 & 10 & 30,3 \\
Roedor & 84 & 22 & 20,8 & 11 & 9 & 45,0 \\
Controle & 20 & 8 & 28,6 & 4 & 1 & 20,0 \\
\hline Total & 299 & 131 & - & 81 & 53 & - \\
Média & - & - & 26,0 & - & - & 29,7 \\
\hline
\end{tabular}

A análise dos dados mês a mês (tabelas $12^{\mathrm{a}}$ e $12 \mathrm{~b}$ ), controlando a noite de coleta e a posição das iscas, mostrou que na maioria das vezes as fềmeas de $L$. intermedia s.l. foram atraídas igualmente pelas diferentes iscas, nos dois ambientes investigados. Entretanto, quando ocorre diferença na atratividade, o cão é o mais selecionado. Somente no mês de agosto, quando ocorreu a maior abundância relativa do número de fêmeas coletadas, ocorreu uma diferença significativa de atratividade do cão em relação ao gambá e roedor no ambiente mata $(p<0,05$, REGW Multiple Range Test) (tabelas 12a e 12b). 
Tabela 12a. Raiz Quadrada do número de fềmeas (Desvio Padrão) de Lutzomyia intermedia coletadas em cada experimento na mata, em armadilhas tipo Disney, sem isca (controle) e com isca (cão, gambá, roedor) na área de Conchal, no período de agosto de 1999 a abril de 2000 .

\begin{tabular}{lccccc}
\hline Mês & \multicolumn{5}{c}{ Mata } \\
\cline { 2 - 6 } & Total & Cão & Gambá & Roedor & Controle \\
\hline Ago/99 & 46 & $2,6^{\mathrm{a}}(0,9)$ & $0,9^{\mathrm{b}}(1,1)$ & $0,8^{\mathrm{b}}(1,1)$ & $0,8^{\mathrm{b}}(1,1)$ \\
Nov/99 & 34 & $1,2^{\mathrm{a}}(1,6)$ & $1,5^{\mathrm{a}}(1,2)$ & $1,2^{\mathrm{a}}(0,9)$ & $0,0^{\mathrm{b}}(0,0)$ \\
Fev/00 & 23 & $1,6^{\mathrm{a}}(0,3)$ & $1,2^{\mathrm{ab}}(0,2)$ & $1,0^{\mathrm{ab}}(0,7)$ & $0,3^{\mathrm{b}}(0,5)$ \\
Abr/00 & 26 & $1,8^{\mathrm{a}}(0,5)$ & $1,1^{\mathrm{a}}(0,8)$ & $0,6^{\mathrm{a}}(0,7)$ & $0,6^{\mathrm{a}}(0,7)$
\end{tabular}

Números na mesma linha com sobrescritos com diferentes letras são significativamente diferentes pelo REGW Multiple Range Test, com $5 \%$ de significância.

Tabela 12b Raiz Quadrada do número de fềmeas (Desvio Padrão) de Lutzomyia intermedia coletadas em cada experimento no peridomicílio, em armadilhas tipo Disney, sem isca (controle) e com isca (cão, gambá, roedor) na área de Conchal, no período de agosto de 1999 a abril de 2000.

\begin{tabular}{lccccc}
\hline Mês & \multicolumn{5}{c}{ Peridomicílio } \\
\cline { 2 - 6 } & Total & Cão & Gambá & Roedor & Controle \\
\hline Ago/99 & 08 & $0,7^{\mathrm{a}}(0,8)$ & $0,6^{\mathrm{a}}(0,7)$ & $0,3^{\mathrm{a}}(0,5)$ & $0,0^{\mathrm{a}}(0,0)$ \\
Nov/99 & 12 & $1,2^{\mathrm{a}}(1,1)$ & $0,5^{\mathrm{a}}(0,6)$ & $0,3^{\mathrm{a}}(0,5)$ & $0,0^{\mathrm{a}}(0,0)$ \\
Fev/00 & 08 & $0,8^{\mathrm{a}}(0,9)$ & $0,3^{\mathrm{a}}(0,5)$ & $0,4^{\mathrm{a}}(0,7)$ & $0,0^{\mathrm{a}}(0,0)$ \\
Abr/00 & 25 & $1,8^{\mathrm{a}}(0,8)$ & $0,9^{\mathrm{ab}}(0,6)$ & $1,1^{\mathrm{ab}}(0,2)$ & $0,3^{\mathrm{b}}(0,5)$
\end{tabular}

Números na mesma linha com sobrescritos com diferentes letras são significativamente diferentes pelo REGW Multiple Range Test, com $5 \%$ de significância. 


\subsubsection{Hábito alimentar}

Nas coletas direcionadas para os prováveis abrigos naturais dos flebotomíneos, pode-se observar que ocorreu uma diferença significativa na distribuição de fềmeas ingurgitadas $\left(\mathrm{X}^{2}=42,8, \mathrm{gl}=3, \mathrm{p}<0,001\right)$, pelos diferentes ambientes pesquisados (tabela 13). O maior número foi coletado no intradomiciilo (32), perfazendo um total de $54,2 \%$ das fềmeas. Do total de 59 fềmeas ingurgitadas, 52 reagiram positivamente para um dos antisoros testados na reação de precipitação (humano, ave, marsupial, roedor e canideo) (tabela13). Das fềmeas coletadas no intradomicilio com reação positiva, $21(77,7 \%)$ alimentaram-se em humanos e 6 $(22,2 \%)$ em cão. Tanto no peridomicílio como na margem da mata prevaleceu a alimentação das fềmeas de L. intermedia s.l. em aves, com $9(50,0 \%)$ e $6(100 \%)$, respectivamente. Ainda no ambiente peridomiciliar, $5(27,7 \%)$ das fềmeas, com reação positiva, alimentaram-se em humanos, $3(16,7 \%)$ em cães e $1(5,5 \%)$ em roedor (tabela 13). Nenhuma alimentação múltipla, definida pela identificação de mais de uma fonte sanguínea tomada por uma fêmea, foi detectada. Muito provavelmente, os testes não reagentes foram devidos a pouca quantidade de sangue encontrado nas fềmeas testadas. No ambiente de mata apenas 2 fềmeas ingurgitadas foram coletadas e somente uma apresentou reação positiva, no caso, para humano. 
Tabela 13. Identificação do sangue ingerido, em número e porcentagem, de fêmeas de L. intermedia s.l. coletadas em diferentes ambientes, na zona rural do município de Conchal, nos períodos de setembro de 1994 a agosto de 1995 e de agosto a dezembro de 1999.

\begin{tabular}{|c|c|c|c|c|c|c|c|}
\hline \multirow[t]{2}{*}{ Ambiente } & \multirow{2}{*}{$\begin{array}{c}\text { Número } \\
\text { de fềmeas } \\
\text { ingurgitadas }\end{array}$} & \multirow{2}{*}{$\begin{array}{l}\text { Número } \\
\text { de testes } \\
\text { reagentes }\end{array}$} & \multicolumn{5}{|c|}{$\begin{array}{c}\text { Número }(\%) \text { de reações positivas para } \\
\text { diferentes anti-soros }\end{array}$} \\
\hline & & & $\mathrm{H}$ & A & $\bar{M}$ & $\mathrm{R}$ & $\mathrm{C}$ \\
\hline Intradomicílio & 32 & 27 & $\begin{array}{c}21 \\
(77,7)\end{array}$ & $\begin{array}{c}0 \\
(0,0)\end{array}$ & $\begin{array}{c}0 \\
(0,0)\end{array}$ & $\begin{array}{c}0 \\
(0,0)\end{array}$ & $\begin{array}{c}6 \\
(22,5)\end{array}$ \\
\hline Peridomicilio & 19 & 18 & $\begin{array}{c}5 \\
(27,7)\end{array}$ & $\begin{array}{c}9 \\
(50,0)\end{array}$ & $\begin{array}{c}0 \\
(0,0)\end{array}$ & $\begin{array}{c}1 \\
(5,5)\end{array}$ & $\begin{array}{c}3 \\
(16,7)\end{array}$ \\
\hline Margem mata & 6 & 6 & $\begin{array}{c}0 \\
(0,0)\end{array}$ & $\begin{array}{c}6 \\
(100)\end{array}$ & $\begin{array}{c}0 \\
(0,0)\end{array}$ & $\begin{array}{c}0 \\
(0,0)\end{array}$ & $\begin{array}{c}0 \\
(0,0)\end{array}$ \\
\hline Mata & 2 & 1 & $\begin{array}{c}1 \\
(100)\end{array}$ & $\begin{array}{c}0 \\
(0,0)\end{array}$ & $\begin{array}{c}0 \\
(0,0)\end{array}$ & $\begin{array}{c}0 \\
(0,0)\end{array}$ & $\begin{array}{c}0 \\
(0,0)\end{array}$ \\
\hline Total & 59 & 52 & $\begin{array}{c}27 \\
(51,9)\end{array}$ & $\begin{array}{c}15 \\
(28,8)\end{array}$ & $\begin{array}{c}0 \\
(0,0)\end{array}$ & $\begin{array}{c}1 \\
(1,9)\end{array}$ & $\begin{array}{c}9 \\
(17,3)\end{array}$ \\
\hline
\end{tabular}

( $\mathrm{H}=$ humano; $\mathrm{A}=$ ave; $\mathrm{M}=$ marsupial; $\mathrm{R}=$ roedor; $\mathrm{C}=$ canídeo) 


\section{DISCUSSÃO}

Lutzomyia intermedia s.l. esteve representada por $99,4 \%$ do total de flebotomineos coletados na zona rural do município de Conchal. A predominância de L. intermedia s.l. em ambientes alterados na Região Sudeste do Brasil tem sido bastante documentada (GOMES e col. 1983; 1986; 1989; GOMES e GALATI 1987; RANGEL e col. 1986; 1990; FALQUETO 1995). Pesquisas extensivas, realizadas na região do Vale do rio Mogi Guaçu, demonstraram que esta predominância apresentase de forma quase que absoluta, mostrando a adaptação dessa espécie nas localidades onde ocorrem pequenos remanescentes de matas ciliares (FORATTINI e col. 1976; GOMES e col. 1989). Também em coletas esporádicas realizadas pela SUCEN, objetivando confirmação de autoctonia dos casos de leishmaniose tegumentar ocorridos em inúmeras localidades desta região, $L$. intermedia s.l. sempre se apresentou como espécie predominante (SES- CVE 1995; SUCEN $^{2}$ ). Na área onde foi realizado este estudo, o encontro de $L$. intermedia s.l. em proporções altas, em todos os meses do ano e com distribuição marcante nos ambientes de mata e domiciliar, já havia sido registrado anteriormente (CASANOVA e col. 1995). Desta forma, alguns pesquisadores sugeriram que $L$. intermedia s.l. desempenhe importante papel na transmissão domiciliar da leishmaniose tegumentar ao homem e na manutenção do ciclo enzoótico, na região Nordeste do Estado de São Paulo (FORATTINI e col. 1976; GOMES e col. 1989; CASANOVA e col. 1995). A predominância desta espécie por toda a região de planície do Vale do rio Mogi Guaçu, onde as inundações anuais das matas ciliares são freqüentes na estação

\footnotetext{
${ }^{2}$ Superintendência de Controle de Endemias-São Paulo: Boletim de Captura de Flebotomineos.
} 
chuvosa, sugere que os estágios imaturos de L. intermedia s.l. estejam melhores adaptados, do que os de outras espécies, a esses terrenos. A constatação do aumento da abundância populacional de L. intermedia s.l., em poucas semanas, após os episódios de inundação, parece indicar que as inundações fornecem condições ótimas para o seu desenvolvimento.

A presença de números inexpressivos de $L$. whitmani e $L$. pessoai, já havia sido assinalada na região do vale do rio Mogi Guaçu (FORATTINI e col. 1976 e col 1976; GOMES e col. 1989; CASANOVA e co. 1995). Embora, L.whitmani não demonstre exercer importante papel na transmissão da leishmaniose tegumentar nesta região, seu alto grau de antropofilia e presença em altas densidades, inclusive no ambiente domiciliar, em outras áreas do Estado de São Paulo, não permite descartar sua participação na transmissão ao homem ou na manutenção do ciclo enzoótico da $L$. braziliensis em algumas localidades. L. whitmani, espécie amplamente distribuída pelo Brasil (YOUNG e DUNCAN 1994), é apontada como principal vetor de espécies de Leishmania (Viannia) em diferentes regiões (MAYRINK e col. 1979; VEXENAT e col. 1986; BRANDÃO-FILHHO e col. 1994; PASSOS e col. 1993; QUEIROZ e col. 1994; AZEVEDO e col. 1996, TEODORO 1995), apresentando diferenças quanto ao grau de adaptação ao ambiente modificado. Recentemente, tem sido observado que esta espécie apresenta também diferenças quanto ao grau de antropofilia (CAMPBELL-LENDRUM e col. 1999), endofilia (CAMPBELL-LENDRUM e col. 2000) e composição genética (RANGEL e col. 1996; ISHIKAWA e col. 1999). Essas variações comportamentais, genéticas e de participação na transmissão da leishmaniose tegumentar, ensejam a realização de estudos sobre parâmetros da capacidade vetorial das populações de $L$. whitmani. 
Mesmo, considerando-se que L. intermedia s.s. e L. neivai constituam o complexo $L$. intermedia e, ainda, que nenhuma destas duas espécies preencham os requisitos para serem consideradas como vetoras comprovadas (KILLICKKENDRICK 1990), ambas têm sido incriminadas como suspeitas na participação da transmissão da leishmaniose tegumentar americana, em suas respectivas áreas de distribuição (MARCONDES 1996; 1997; MARCONDES e col. 1998). No Brasil este complexo tem uma distribuição conhecida desde o estado do Piauí até o Rio Grande do Sul. Na região Sudeste L. intermedia s.s. foi encontrada nos Estados do Rio de Janeiro, Espírito Santo, a leste de Minas Gerais e em São Paulo, a leste da Serra do Mar, sendo o litoral deste Estado seu limite extremo sul. L. neivai foi encontrada desde o oeste de Minas Gerais, extremo norte de sua distribuição, até o Rio Grande do Sul, sendo que em São Paulo ocorreu na Serra do mar e a oeste desta (MARCONDES 1997; MARCONDES e col. 1998). Portanto, muito provavelmente, os exemplares de L.intermedia coletados na zona rural do município de Conchal e em todo o Vale do rio Mogi Guaçu, pertenceriam a $L$. neivai. Como, já sugerido por MARCNDES ecol. (1998), essa possivel divisão do complexo L. intermedia, torna clara a importância de realização de estudos que permitam determinar as localidades e regiões em que cada uma destas espécies ocorre e verificar possíveis diferenças nos parâmetros ecológicos de capacidade e competência vetorial das mesmas. Tais investigações poderão fornecer subsídios para o entendimento da distribuição de casos de leishmaniose tegumentar nas várias regiões do Estado de São Paulo.

Os dados de dispersão ambiental e dos parâmetros populacionais de $L$. intermedia s.l., componentes importantes para o entendimento do potencial desta espécie para atuar como vetora da leishmaniose tegumentar americana, só puderam 
ser obtidos, em campo, pelo cumprimento dos pré-requisitos indispensáveis para uso da técnica de marcação-soltura-recaptura. A condição de que a marcação não afete a sobrevivência dos individuos, e que estes permaneçam marcados por toda vida, ou pelo menos, durante o período do experimento (SOUTHWOOD 1978; BEGON 1979) foi satisfeita. O teste realizado em laboratório, com exemplares machos e fềmeas de L. intermedia s.l., mostrou que o pó fluorescente e a técnica empregada para a marcação dos flebotomíneos foi eficaz, pois não afetou a sobrevivência dos indivíduos marcados e todos permaneceram marcados até o final do experimento. Outros estudos realizados com flebotomíneos, embora empregando procedimentos diferentes para realizar a marcação, também demonstraram que o uso do pó fluorescente não afetava a sobrevivência dos indivíduos (CHANIOTIS e col. 1974; MORRISON e col. 1993; PARDO e col. 1996).

Outros requisitos que também devem ser considerados para verificar a adequação da técnica de marcação são: os indivíduos marcados devem se misturar à população e devem ser amostrados aleatoriamente, independentemente de estarem marcados; o período de amostragem deve ser curto e discreto e; as taxas de adição e de perda devem ser insignificantes ou estimadas (SOUTHWOOD 1978; BEGON 1979).

Com relação ao requisito de que os indivíduos marcados devam se misturar à população e ser amostrados aleatoriamente, verificou-se neste estudo, que os indivíduos marcados e não marcados foram coletados em praticamente todas as armadilhas, sempre com uma maior proporção de não marcados. Considerou-se portanto, que os indivíduos marcados se misturaram à população. Por outro lado, os indivíduos marcados com pó fluorescente não são distinguiveis a olho nu, e portanto 
sua amostragem foi aleatória. As coletas dos flebotomíneos foram realizadas em períodos de 3 horas por noite, em 5 a 7 dias seguidos após a soltura, atendendo ao requisito de períodos de amostragem curtos e discretos. Finalmente, devido ao isolamento da área de estudo, a qual possui barreiras fisicas bem nítidas, representadas pelo rio e pelas extensas áreas abertas, considerou-se insignificante a ocorrência de imigração e emigração de indivíduos durante o período de estudo. Desta forma, a técnica de marcação empregada foi considerada confiável e satisfatória para a realização de estudos em campo, visando obter dados sobre a dispersão ambiental e os parâmetros populacionais de L. intermedia s.l. .

Com relação à taxa de recaptura, verificou-se que a taxa total de $7,6 \%$, obtida para $L$. intermedia s.l., foi comparável àquelas obtidas em outros estudos realizados com diferentes espécies do Novo Mundo (CHANIOTIS e col. 1974; DYE e col. 1991; ALEXANDER e YOUNG 1992; MORRISON e col. 1993; PARDO e col 1996). A maior taxa de recaptura de machos de L. intermedia $s . l$, em relação às fềmeas, nas coletas com armadilhas de Shannon, pode estar relacionada com a tendência dos machos se deslocarem menos do que as fềmeas, conforme demonstrado pela média aritmética, amplitude máxima e média diária de dispersão

Os resultados dos experimentos de dispersão mostram que L. intermedia s.l. não se desloca a longas distâncias na área de estudo. A média aritmética de distância de dispersão foi igual a $53 \mathrm{~m}$, sendo que aproximadamente $90 \%$ dos individuos, tanto machos como fềmeas, foram recapturados a menos de $70 \mathrm{~m}$ do ponto de soltura. Nas armadilhas CDC situadas entre 100 e 160 metros de distância do ponto de soltura, apenas dois exemplares foram recapturados. Nenhum exemplar foi recapturado nas armadilhas dispostas a $160 \mathrm{~m}$ do ponto de soltura. No entanto, é importante salientar 
que uma fềmea, solta na margem da mata, atravessou $128 \mathrm{~m}$ para alcançar um dos peridomicilios da área. Uma vez que os flebotomíneos recapturados não foram soltos novamente, a chance de realizarem dispersão por distâncias maiores a partir do ponto da recaptura, não pode ser investigada. No entanto, também a estimativa de distância média de dispersão diária, mostrou que no período compreendido entre 2 a 7 dias após a soltura, os indivíduos mantiveram-se a distâncias inferiores a $60 \mathrm{~m}$ do ponto de soltura. Essas distâncias de dispersão de $L$. intermedia s.l. são semelhantes àquelas observadas para outras espécies de flebotomíneos da região neotropical (CHANIOTIS 1974; ALEXANDER 1987; ALEXANDER e YOUNG 1992), mas são inferiores às distâncias encontradas para os flebotomíneos de regiões áridas e semiáridas do Velho Mundo, para os quais foram registradas dispersões acima de $1 \mathrm{~km}$ (KILLICK-KENDRICH e col. 1984; DOHA e col. 1991). Possivelmente, a tendência de dispersão baixa encontrada para $L$. intermedia $s . l$. esteja relacionada à alta disponibilidade de alimento e de abrigos naturais, cuja falta, serviriam de estímulo à dispersão. Assim, os flebotomíneos de áreas de mata estariam menos motivados a abandonar seu ambiente do que os flebotomíneos que habitam áreas com condições ambientais mais rigorosas, como aquelas das regiões áridas (CHANIOTIS e col. 1974; ALEXANDER e YOUNG 1992). Em área de floresta úmida do Panamá, CHANIOTIS e col. (1974), recapturaram cerca de $90 \%$ dos flebotomíneos a menos de $60 \mathrm{~m}$ dos pontos de soltura e somente 4 indivíduos a $200 \mathrm{~m}$ de distância. $\mathrm{Na}$ Colômbia, em área de plantação de café entremeada por árvores de grande porte, remanescentes de floresta original, aproximadamente $74 \%$ dos flebotomíneos, representados por várias espécies, foram recapturados a distâncias inferiores a $80 \mathrm{~m}$. Posteriormente, nessa mesma área, ALEXANDER e YOUNG (1992), demınstraram 
que a maioria dos flebotomíneos foi recapturada a até $200 \mathrm{~m}$ do ponto de soltura e, chamaram a atenção para o fato de que uma fềmea de Lutzomyia gomezi, 11 dias após a soltura, ter se dispersado por quase $1 \mathrm{~km}$. Em outra área da Colômbia, em região endêmica de leishmaniose visceral, foi observado que do total de indivíduos de $L$. longipalpis recapturados, $49 \%$ foram coletados a distâncias menores do que $50 \mathrm{~m}$, $48 \%$ entre 100 e $300 \mathrm{~m}$ e, apenas, $3 \%$ a distâncias maiores do que $500 \mathrm{~m}$ (MORRISON e col. 1993). No Estado do Pará, no Brasil, DYE e col. (1991), recapturaram a maioria dos exemplares de L. longipalpis a distâncias menores do que $100 \mathrm{~m}$ e um único exemplar macho a $700 \mathrm{~m}$ do ponto de soltura.

Pelas coletas realizadas com armadilhas de Shannon, também pode ser observado que em praticamente todos os meses, os individuos de L. intermedia s.l. soltos na margem da mata, apresentaram uma maior tendência a se dispersarem em direção ao interior da mata e, em menor grau, se deslocarem pela margem da mata. A tendência de dispersão para o ambiente peridomiciliar observada no mês de abril de 2000 e, em proporções relativas menores, nos outros meses de estudo, demonstrou que $L$. intermedia s.l. pode se deslocar da mata e alcançar o ambiente domiciliar, localizado na área de estudo a distâncias de até $70 \mathrm{~m}$.

Levando-se em conta o padrão de dispersão de L. intermedia s.l. na área de estudo e assumindo que a transmissão ao homem na região ocorre, principalmente, no ambiente domiciliar (TOLEZANO 1994; MASCARINI e col. 1995), a origem da infecção neste ambiente pode ser pensada em termos de que a partir de um ciclo enzoótico na mata as fềmeas infectadas alcançariam os domicílios situados a menos de $130 \mathrm{~m}$ e, assim, transmitiriam a infecção ao homem e animais domésticos. Uma provável origem da infecção nos vetores adaptados ao ambiente domiciliar, a partir de 
mamíferos silvestres que habitam as matas residuais, já foi sugerida por LAINSON (1989) e LAINSON e col. (1994).

Por outro lado, as evidências de existência de criadouros de $L$. intermedia s.l. no ambiente peridomiciliar, na região de estudo (CASANOVA 2000), deixam em aberto a possibilidade de ocorrência de ciclos extraflorestais com a participação de animais domésticos como reservatórios da Leishmania braziliensis, ou da entrada de animais silvestres infectados no ambiente peridomiciliar.

O conhecimento da dispersão de um vetor é útil na determinação da taxa potencial de disseminação de um patógeno. Assim, este estudo parece indicar que $L$. intermedia s.l., apresentando baixas distâncias de dispersão, deve enquanto vetor, manter o patógeno circulando em áreas restritas, explicando a ocorrência de casos focais, como ocorre na região do Vale do rio Mogi Guaçu.

A criação de "zonas livres" de vegetação em torno dos domicilios, como alternativa ao controle químico, se colocada em prática em regiões onde $L$. intermedia s.l. é a espécie predominante, deveria levar em conta a amplitude máxima de vôo, de aproximadamente $130 \mathrm{~m}$, demonstrada no presente estudo.

Embora definido de vários modos, o ciclo gonotrófico de uma espécie, tem sido considerado mais comumente como o intervalo de tempo entre um repasto sanguíneo e a oviposição (SERVICE 1993). Desta forma, o tempo de duração do ciclo gonotrófico de L. intermedia s.l. estimado, neste estudo, em condições naturais, foi, aproximadamente, de 3,5 dias. Provavelmente, algumas das fềmeas recapturadas, sem sangue ou ovos no abdômen, na quarta noite após a alimentação, estariam aptas a realizar um outro repasto sanguíneo. Para esta mesma espécie, GOMES e col. (1982), em ecótopo artificial, observaram que a duração do ciclo gonotrófico variou ù 6 a 10 
dias, e RANGEL e col. (1985), em condições de laboratório, encontraram o pico de desova no $5^{\circ}$ dia após a alimentação sanguínea. Estes autores também constataram a ocorrência de concordância gonotrófica em L. intermedia s.l.. Em experimentos de marcação-soltura-recaptura na França, KILLICK-KENDRICK e GUY (1981) citado por KILLICK-KENDRICK (1991), observaram que a oviposição de Phlebotomus ariasi ocorria, normalmente, no $6^{\circ}$ dia após a alimentação sanguínea e a procura por nova alimentação ocorria a partir do dia seguinte a oviposição.

O sucesso em adquirir uma refeição sanguínea e a duração do ciclo gonotrófico determinam a freqüência de contato homem-vetor e, assim, a eficiência e a taxa de transmissão de um parasita. Caso, um novo repasto sanguíneo seja realizado no mesmo dia, ou no dia seguinte, após a oviposição, $L$. intermedia s.l. teria o potencial de se alimentar a cada 3, 4 ou 5 dias. Caso, as fềmeas de L. intermedia s.l. tornem-se infectantes com Leishmania braziliensis a partir do $3^{\circ}$ dia após o repasto sanguíneo infectivo, quando já pode ser observado um aumento expressivo do número de formas promastigotas no intestino médio, ou a partir do $5^{\circ}$ dia, quando uma infecção massiva de formas promastigotas já pode ser observada na válvula esofagiana (RANGEL e col. 1992) então, na realização do segundo repasto sanguíneo, uma proporção das fềmeas já poderia transmitir o parasita.

A sobrevivência diária é reconhecida como o parâmetro que causa maior impacto sobre o potencial de transmissão de uma espécie vetora, uma vez que a expectativa de vida do vetor determina o seu tempo de vida infectante. A taxa de sobrevivência diária de aproximadamente $67,5 \%$ encontrada para L. intermedia s.l. na zona rural do município de Conchal, reflete uma expectativa de vida de 2,54 dias. Esta expectativa de vida, associada a uma duração média de 3,5 dias to ciclo 
gonotrófico, indica que grande parte da população de fềmeas não sobreviveria após a primeira oviposição. Estes resultados sugerem que, provavelmente, não com taxas tão altas, a mortalidade de fềmeas durante a oviposição, freqüentemente observada em laboratório, também deve ocorrer na natureza.

Considerando-se que o ciclo de Leishmania braziliensis no vetor ocorra entre 3 e 5 dias (RANGEL e col. 1992), tem-se que a probabilidade média das fềmeas de $L$. intermedia s.l. sobreviverem o suficiente para transmitir o parasita $\left(\mathrm{s}^{\mathrm{n}}\right)$ será de aproximadamente $22,3 \%$ (variando entre $0,6743^{3}=30,7 \%$ e $0,6743^{5}=13,9 \%$ ), onde $s$ é a taxa de sobrevivência diária e $n$ é a duração do ciclo do parasita no vetor. Essa baixa proporção de flebotomíneos que alcançam uma idade na qual podem se tornar infectantes permite supor que $L$. intermedia s.l. não tenha um potencial alto para realizar a transmissão. Esses valores podem explicar a baixa endemicidade da doença na região de estudo. Por outro lado, fica demonstrada a capacidade de $L$. intermedia s.l. realizar a transmissão da Leishmania pois, a sobrevivência de uma parte da população de fềmeas por mais de 10 dias e a possibilidade das mesmas realizarem uma refeição sanguínea, em média, a cada 4 dias, indica que estas fềmeas têm o potencial de realizar pelo menos 3 alimentações durante sua vida.

Neste sentido, pode-se inferir pelas observações acima, que altas densidades de fềmeas de $L$. intermedia s.l. poderiam compensar sua baixa taxa de sobrevivência e, assim, conferir um aumento no potencial de transmissão. No estudo ficou evidenciada uma grande diferença mensal na abundância absoluta da população de $L$. intemedia, a qual variou, para as fềmeas de 2.462 no mês de setembro de 1999 a 20.637 no mês de novembro de 1999. A aplicação de uma sobrevivência diária de 0,6743 a essa população resultaria, por exemplo, ao final de 3 a 5 dias (tempo 
estimado do ciclo do parasita no vetor) em 755 ou 343 fềmeas para o mês de setembro de 1999, e 6.327 ou 2.877 fềmeas para o mês de novembro de 1999, com conseqüências epidemiológicas bastante distintas. Assim, considerando-se uma mesma taxa de sobrevivência diária para todos os meses do ano, pode-se supor que aqueles que apresentaram maiores densidades populacionais representariam maior risco para a ocorrência de transmissão da leishmaniose tegumentar. A inexistência de dados referentes à sobrevivência de flebotomíneos, em condições naturais, não permite que sejam feitas comparações com as estimativas e projeções obtidas neste estudo.

Quanto ao comportamento alimentar, as fêmeas de L. intermedia s.l. não demonstraram possuir uma nítida preferência por qualquer um dos animais oferecido como iscas (cão, gambá e roedor), em nenhum dos dois ambientes investigados (interior da mata e peridomiciliar), sugerindo um comportamento oportunista em relação à escolha de alimento. No entanto, na única ocasião em que ocorreu uma diferença significativa na atração de alguma das iscas, ela se deu a favor do cão oferecido no ambiente de mata. Não se pode descartar a possibilidade de que essa maior tendência observada de atração pelo cão, pode estar relacionada ao seu maior tamanho, quando comparado ao gambá e roedor. QUINELL e col. (1992), observaram na Ilha de Marajó, para L. longipalpis, que a atratividade pelos hospedeiros utilizados em seus experimentos tinha uma relação positiva com o maior tamanho e/ou número dos mesmos. Esta mesma relação com o tamanho do hospedeiro foi sugerida para L. whitmani, de diferentes regiões do Brasil (CAMPBELL-LENDRUM e col. 1999) e para L. whitmani e L. intermedia, em experimentos realizados em uma localidade do Estado do Paraná (PINTO e col. 2001). Diferentemente, outros estudos realizados com diferentes espécies de 
flebotomíneos indicaram a ocorrência de preferência independentemente do tamanho dos hospedeiros oferecidos como iscas (SHAW e LAINSON 1968; CHRISTENSEN e HERRER 1980; AGUIAR e col. 1987; MONTOYA-LERMA e LANE 1996). Em duas áreas endêmicas de leishmaniose tegumentar do Estado do Espírito Santo, FALQUETO (1995), encontrou diferença na atratividade do cão e de vários animais silvestres para diferentes espécies de flebotomíneos, sendo que L. intermedia s.l. apresentou alta atratividade pelo cão.

O fato de $L$. intermedia s.l. ter apresentado um comportamento oportunista em relação à escolha dos hospedeiros utilizados nos experimentos, e de serem estes representantes dos grupos de animais reconhecidos como possiveis reservatórios silvestres (gambá e roedor), ou domésticos (cão), apontam para a possibilidade de sua atuação na manutenção do ciclo enzoótico e/ou domiciliar da leishmaniose.

Embora, os machos de L. intermedia s.l. não se alimentem de sangue, eles parecem ser atraídos pelas iscas e podem, como observado em L. longipalpis, exercer importante papel na atratividade das fềmeas. QUINELL e DYE (1994) e KELLY e DYE (1997) notaram que os ferormônios liberados pelos machos de L. longipalpis, agregados em grande número sobre os hospedeiros ou nas proximidades destes, atuavam como atrativos sobre as fềmeas.

Segundo BRAY (1982), o animal reservatório ideal para as espécies de Leishmania deve, entre outras características, ser atrativo e servir como fonte principal de alimento para as fềmeas de flebotomíneos. Este dado é normalmente alcançado com a identificação sorológica do sangue ingerido pelos flebotomíneos. O presente estudo, apresenta a primeira tentativa de determinação do comportamento alimentar de L. intermedia s.l., baseada na identificação do sangue ingerido na 
natureza. Os resultados obtidos também mostraram o comportamento oportunista da espécie pois, nos diferentes ambientes investigados, a maior disponibilidade de um tipo de hospedeiro serviu como fonte de alimentação para uma maior proporção de fềmeas ingurgitadas. Como, a leishmaniose tegumentar é uma zoonose e o homem representa um hospedeiro acidental, torna-se evidente que a transmissão ao homem deve ser feita por vetores oportunistas, que incluam o homem e os animais reservatórios como fontes de alimentação.

Embora, ocorrendo em proporções muito diferentes, a participação do homem e do cão (no ambiente intradomiciliar), e do homem, do cão e do roedor (no ambiente peridomiciliar), como fontes de alimentação para $L$. intermedia s.l., demonstra que esses ambientes seriam suscetíveis à introdução e circulação do parasita responsável pela leishmaniose na área de estudo. Assim, levando-se em conta apenas o comportamento alimentar, a taxa de transmissão do parasita poderia ser influenciada pela quantidade de fontes de infecção disponíveis na área. Alguns pesquisadores questionam o papel do cão como reservatório da Leishmania, mas, apontam para a importância dos mamíferos silvestres servirem como fonte de infecção para a população de flebotomíneos do ambiente peridomociliar (GOMES e col. 1989; 1990; GOMES 1994) ou daqueles do ambiente próximo às matas (LAINSON 1989), os quais poderiam, posteriormente, transmitir o parasita ao homem no ambiente domiciliar.

Observações sobre distribuição mensal e sazonal, dispersão, duração do ciclo gonotrófico, sobrevivência e comportamento alimentar, permitiram avaliar o potencial biológico de L. intermedia s.l. como vetor da leishmaniose tegumentar na zona rural do município de Conchal. O estudo indicou um baixo potencial de transmissão, caso 
fosse levado em conta apenas os resultados da taxa de sobrevivência diária. A expectativa de vida, resultante dessa taxa, demonstra que apenas uma pequena proporção da população de fêmeas atingiria idade na qual elas podem se tornar infectantes. No entanto, outros fatores que permitem estimar o potencial de transmissão, tais como: a curta duração do ciclo gonotrófico, que aumenta a freqüência de picadas; o comportamento alimentar, que mostrou ser oportunista e com alta proporção de sangue humano no ambiente domiciliar; a dispersão ambiental, que indicou a possibilidade de uma parte da população alcançar o ambiente domiciliar e; finalmente, a alta densidade absoluta, alcançada em alguns meses do ano, podem compensar a baixa sobrevivência e a correspondente expectativa de vida estimada para a população de $L$. intermedia s.l. na área de estudo.

Esta avaliação do potencial de transmissão de $L$. intermedia s.l. tem correspondência com o padrão epidemiológico da leishmaniose tegumentar no Estado de São Paulo, particularmente na região de estudo, que se caracteriza por apresentar casos esporádicos ou microfocos, baixa incidência de casos e com transmissão ocorrendo, principalmente, no ambiente domiciliar. 


\section{CONCLUSÕES}

Lutzomyia intermedia é a espécie predominante na zona rural do município de Conchal, está presente em todos os meses do ano e se distribui preferencialmente no interior de matas ciliares residuais e no peridomicílio de residências próximas a essas matas.

A dispersão ambiental de $L$. intermedia s.l. parece ser baixa. Os indivíduos se deslocaram por distâncias de até 120 m mas, a maioria das recapturas, ocorreram a distâncias menores do que $70 \mathrm{~m}$. Foi observado que exemplares soltos na margem da mata alcançaram os domicilios.

A taxa de sobrevivência diária estimada para os individuos de $L$. intermedia s.l. foi de aproximadamente $67,5 \%$, resultando numa expectativa de vida baixa, menor do que 3 dias, e indicando que uma baixa proporção de fềmeas alcançaria idades infectantes.

O ciclo gonotrófico, estimado em condições naturais, foi completado em 3 ou 4 dias, indicando que o contato homem-vetor pode ocorrer, em média, a cada 4 dias. Este tempo, associado à constatação de que pelo menos parte da população de fềmeas sobrevive por mais de 10 dias, demonstra a possibilidade destas fêmeas realizarem até 3 alimentações durante a vida.

O comportamento alimentar de $L$. intermedia s.l. é oportunista pois, ajusta seu padrão de alimentação à disponibilidade de hospedeiros. No ambiente domiciliar, a taxa de alimentação no homem foi prevalente.

Tendo em vista os diversos parâmetros ecológicos estimados, tais como, um comportamento alimentar oportunista, alta freqüência de alimentaçã e alta 
abundância da população em determinados meses do ano, pode-se concluir que $L$. intermedia s.l. tem potencial biológico para atuar como vetor da leishmaniose tegumentar. No entanto, a baixa taxa de sobrevivência diária estimada e a baixa expectativa de vida encontrada, sugere que este potencial seja baixo, o que está em concordância com o a baixa incidência da endemia na região de estudo 


\section{REFERÊNCIAS BIBLIOGRÁFICAS}

Aguiar GM, Vilela ML, Soucasaux T. Aspectos da ecologia dos flebótomos do Parque Nacional da Serra dos Órgãos, estado do Rio de Janeiro. V. Preferências Alimentares (Diptera, Psychodidae, Phlebotominae). Mem Inst Oswaldo Cruz 1986; 81(4):477-9.

Aguiar GM, Vilela, ML, Lima BR. Ecology of the sand flies of Itaguaí, an area of cutaneous leishmaniasis in state of Rio de Janeiro. Food preferences. (Diptera, Psychodidae, Phlebotominae). Mem Inst Oswaldo Cruz 1987; 82(4): 583-4.

Alexander JB. Dispersal of phlebotomine sand flies (Diptera: Psychodidae) in a Colombia coffee plantation. J Med Entomol 1987; 24: 552-8.

Alexander JB, Young DG. Dispersal of phlebotomine sand flies (Diptera: Psychodidae) in a Colombian focus of Leishmania (Viannia) braziliensis. Mem Inst Oswaldo Cruz 1992; 87: 397-403.

Azevedo ACR, Vilela ML, Souza NA Andrade Coelho CA, Barbosa AF, Firmo ALS, Rangel EF. The sandfly fauna (Diptera: Psychodidae: Phlebotominae) of a focus of cutaneous leishmaniasis in Ilhéus, State of Bahia, Brazil. Mem Inst Oswaldo Cruz 1996; $91(1): 75-79$. 
Bailey NT. Improvements in the interpretation of recapture data. J Anim Ecol 1952; 21: $120-127$.

Begon M. Investigating animal abundance: capture-recapture for biologists. London: Edward Arnold; 1979.

Brandão-Filho SP, Carvalho FG, Brito MEF, Almeida FA, Nascimento LA. American cutaneous leishmaniasis in Pernambuco, Brazil: eco-eoidemiological aspects in Zona da Mata Region. 1994 Mem Inst Oswaldo Cruz 1994; 89 (3): 445-449.

Bray RS. The zoonotic potencial of reservoirs of leishmaniasis in the old world. Ecol Disease 1982; 1(4): 257-67.

Brenner JR, Wargo MJ, Stains GS, Mulla MS. The Dispersal of Culicoides mohave (Diptera: Ceratopogonidae) in the desert of southern California. Mosquito News 1984; $44: 343-350$.

Camargo-Neves VLF. Características da transmissão da leishmaniose tegumentar americana no estado de São Paulo, Brasil. São Paulo; 1999. [Dissertação de Mestrado - Faculdade de Saúde Pública da USP].

Campbell-Lendrum DH, Brandão-Filho SP, Ready PD, Davies CR. Host and/or site loyalt of Lutzomyia whitmani (Diptera: Psychodidae) in Brazil. Med Vet Entomol 1999, 13: 209-211. 
Campbell-Lendrum DH, Pinto MC, Brandão-Filho SP, Souza AA, Ready PD, Davies

CR. Experimental comparison of anthropophily between geographical dispersed populations of Lutzomyia whitmani (Diptera: Psychodidae). Med Vet Entomol 1999, 13: 299-309.

Campbell-Lendrum DH, Brandão-Filho SP Pinto MC, Ready PD, Davies CR. Domesticity of Lutzomyia whitmani (Diptera: Psychodidae) populations: field experiments indicate behavioural differences. Bull Entomol Res 2000, 90: 41-48.

Casanova C, Mayo RC, Rangel O, Mascarini LM, Pignatti MG, Galati EAB, Gomes AC. Natural Lutzomyia intermedia (Lutz \& Neiva) infection in the Valley of MogiGuaçú River, State of São Paulo, Brazil. Bol Dir Malariol y San Amb 1995; 35(Supl. 1): 77- 84.

Casanova C. A soil emergence trap for collections of phlebotomine sand flies. Mem Inst Oswaldo Cruz 2000; 96(2): 273-275.

Chaniotis $\mathrm{BN}$, Correa MA, Tesh RD, Johnson KM. Horizontal and vertical movements of phlebotomine sand flies in a Panamanian rain forest. J Med Entomol $1974 ; 11: 363-75$.

Christensen HA, Herrer A. Panamanian Lutzomia (Diptera: Psychodidae)) host attraction profiles. J Med Entomol 1980; 17(6): 522-28. 
Christensen HA, Vasquez AM. The tree-buttress biotope: a pathobiocenose of Leishmania braziliensis. Am Soc Trop Med Hyg. 1982; 31(2): 243-51.

Christensen HA, Arias JR, Vasquez AM, Freitas R. Hosts of sand fly vectors of Leishmania braziliensis guyanensis in the Central Amazon of Brazil. Am J Trop Med Hyg, 1982; 31: 239-242.

Christensen HA, Fairchild GB, Herrer A, Jonhson CM, Young DG, Vasquez AM. The ecology of cutaneous leishmaniases in the Republic of Panama. J Med Entomol 1983; 20: 463-484.

Disney RHL. A trap for phlebotomine sand flies attracted to rats. Bul Entomol Res 1966; 56: 445-51.

Doha S, Shehata MG, El Said S, El Sawaf B. Dispersal of Phlebotomus papatasi (Scopoli) and P. langeroni Nitzulescu in El Hammam, Matrouh Governorate, Egypt. Ann Parasitol Hum Comp 1991; 66: 69-76.

Dye C, Davies CR, Lainson R. Communication among phlebotomine sandflies: a field study of domesticated Lutzomia longipalpis populations in Amazonian Brazil. Anim Behav 1991; 42: 183-192. 
Falqueto A. Especificidade alimentar de flebotomíneos em duas áreas endêmicas de leishmaniose tegumentar no Estado do Espírito Santo. Rio de Janeiro; 1995. [Tese de Doutorado - Instituto Osvaldo Cruz -FIOCRUZ].

Falqueto A, Grimaldi Jr G, Sessa, PA, Varejão JBM, Deane LM. Lutzomyia gasparviannai, Martins, Godoy \& Silva, 1962, probable vector of Leishmania mexicana ssp. in Viana municipality, Espirito Santo State, Brazil. Mem Inst Oswaldo Cruz 1985; 80(4): 497.

Forattini OP, Pattoli DGB, Rabello EX, Ferreira OA. Infecções naturais de mamíferos silvestres em área endêmica de leishmaniose tegumentar do Estado de São Paulo, Brasil. Rev Saúde Pública 1972a; 6: 255-61.

Forattini OP, Pattoli DBG, Rabello EX, Ferreira OA. Infecção natural de flebotomíneos em foco enzoótico de leishmaniose tegumentar no Estado de São Paulo, Brasil. Rev Saúde Pública 1972b; 6: 431-33.

Forattini OP, Pattoli DGB, Rabello EX, Ferreira OA. Nota sobre infecção natural de Oryzomys capito laticeps em foco enzoótico de leishmaniose tegumentar no Estado de São Paulo, Brasil. Rev Saúde Pública 1973; 7: 181-4.

Forattini OP, Rabello EX, Serra OP, Cotrim MD, Galati EAB, Barata JMS. Observações sobre a transmissão da Leishmaniose Tegumentar no Estado de São Paulo, Brazil. Rev Saúde Pública 1976; 10: 31-43. 
Forattini OP, Gomes AC, Natal D. Kakitani I, Marucci D. Preferências alimentares de mosquitos Culicidae no Vale do Ribeira, São Paulo, Brazil. Rev Saúde Pública 1987; 21: 171-87.

Garret-Jones C. The human blood index of malaria vectors in relation to epidemiological assessment. Bull Wld HIth 1964; 30: 241-261.

Gibbs PE, Leitão-Filho HF. Floristic composition of an area of gallery forest near Mogi Guaçú, state of São Paulo, SE Brazil. Rev Bras Bot. 1978; 1: 151 -156.

Gilles MT. Studies on the dispersion and suvival of Anopheles gambiae Giles in east Africa, by means of marking and release experiments. Bull Entomol Res 1961; 52: 99-127.

Gomes AC, Rabello EX, Santos JLF, Galati EAB. Aspectos Ecológicos da Leishmaniose Tegumentar Americana. 1-Estudo Experimental da freqüência de flebotomíneos a ecótopos artificiais com referência especial a Psychodopygus intermedius. Rev Saúde Pública 1980; 14: 540-56.

Gomes AC, Rabello EX, Santos JLF, Galati EAB. Aspectos Ecológicos da Leishmaniose Tegumentar Americana. 2-Ecótopo artificial como abrigo de Psychodopygus intermedius e observações sobre alimentação e reprodução sob influência de fatores físicos naturais. Rev Saúde Pública 1982; 16: 149-59. 
Gomes AC, Rabello EX, Santos JLF, Galati EAB. Aspectos Ecológicos da Leishmaniose Tegumentar Americana. 3-Observações naturais sobre o ritmo diário da atividade de Psychodopygus intermedius em ambiente florestal e extraflorestal. Rev Saúde Pública 1983; 17: 23-30.

Gomes AC, Santos JLF, Galati EAB. Ecological aspects of American cutaneous leishmaniasis. 4-Observations on the endophilic behavior of the sand fly and the vectorial role of Psychodopygus intermedius in the Ribeira Valley region of the São Paulo State. Brasil. Rev Saúde Pública 1986; 20(4): 280-87.

Gomes AC, Galati EAB. Aspectos ecológicos da Leishmaniose Tegumentar Americana. 5-Estratificação da atividade espacial e estacional de Phlebotominae (Diptera, Psychodidae) em áreas de cultura agricola da região do Vale do Ribeira, Estado de São Paulo, Brasil. Rev Saúde Pública 1987; 23(2): 136-42.

Gomes AC, Barata JMS, Rocha e Silva EO. Galati EAB. Aspectos ecológicos da leishmaniose tegumentar americana. 6-Fauna flebotomínea antropófila de matas residuais situadas na região centro-nordeste do Estado de São Paulo, Brasil. Rev Inst Med Trop 1989; 31(1): 32- 39.

Gomes AC, Ottati SM, Shaw JJ, Lainson R, Yamamoto YI. Active transmission of Leishmania braziliensis brasiliensis in the Serra do Mar Forest, São Paulo, Brasil. Trans R S Trop Med Hyg 1989; 83: 193. 
Gomes AC. Coutinho SG, Paim GV, Ottati SM. Galati EAB, Nunes MP, Capinzaiki AN, Yamamoto YI, Rotter P Avaliação da atividade enzoótica de Leishmania (Viannia) braziliensis, em ambiente florestal e peridomociliar, região do Vale do Ribeira, Estado de São Paulo. Rev Inst Med Trop 1989; 32(2): 105- 115.

Gomes AC. Perfil epidemiológico da leishmaniose tegumentar americana no Brasil. An bras Dermatol 1992; 67: 55-60.

Gomes AC. Sand fly vectorial ecology in the State of São Paulo. Mem Inst Oswaldo Cruz 1994; 89(3): 457-60.

Grimaldi GJr, Tresh RB, McMahon-Pratt D. A review of the geographic distribution and epidemiology of leishmaniasis in the New World. Am J Trop Med Hyg 1989; 41: 687-725.

Guy MW, Killick-Kendrick R, Gill GS, Rioux JA Bray RS. Determination of the hosts of Phlebotomus ariasi Tonnoir, 1921 in the Cévennes by bloodmeal analyses. Ann Parasitol Hum Comp 1984; (5): 449-458.

Ishikawa EAY, Ready PD, Souza AA, Day JC, Rangel EF, Davies CR, Shaw JJ. A mitochondrial DNA phylogeny indicates close realationships between populations of Lutzomyia whitmani (Diptera: Psychodidae, Plebotominae) from the rain-forest Regions of Amazônia and Northeast Brazil. Mem Inst Oswaldo Cruz 1999; 94 : 339 345. 
Jensen T, Washino RK. An assessment of the biological capacity of a sacramento valley population of Aedes melanimon to vector arboviruses. Am J Trop Med Hyg $1991 ; 44(4): 355-363$.

Katz G. Epidemiologia da leishmaniose tegumentar americana no estado de São Paulo, período de 1986 a 1995. São Paulo; 1997. [Dissertação de Mestrado Faculdade de Medicina da USP].

Kelly DW, Dye C. Pheromones, kairomones and the aggregation dynamics of the sandfly Lutzomia longipalpis. Anim Behav 1997; 53: 721-31.

Kramer VL, Carper ER, Beesley C, Reisen WK. Mark-release-recapture studies with Aedes dorsalis (Diptera: Culicidae) in coastal northern California. J Med Entomol $1995 ; 32: 375-380$.

Killick-Kendrick R. Recent advances and outstanding problems in the biology of phlebotomine sand flies. Acta Tropica 1978; 35: 297-313.

Killick-Kendrick R. Ward RD. The ecology of Leishmania. Proc. 3rd Env.Multicoll. Parasitology. Cambridge. Parasitology 1981; 82: 143-152. 
Killick-Kendrick R, Rioux JA. Bailly M, Guy MW, Wilkes TJ, Guy FM, Davidson I, Knechtli R, Ward RD, Guilvard E, Perieres J, Dubois H. Ecology of leishmaniasis in the South of France. 20-Dispersal of Phlebotomus ariasi Tonnoir, 1921 as a factor in the spread of the visceral leishmaniasis in the Cévennes. Ann Parasitol Hum Comp 1984; 59: 555-72.

Killick-Kendrick R. Phlebotomine vectors of the leishmaniases: a review. Med Veter Entomol 1990; 4: 1-24.

Killick-Kendrick R Biology of phlebotomine sandflies: a key factor in the transmission of the leishmaniases. Mem Inst Oswaldo Cruz 1991; 86: 19-20.

Lainson R, Shaw JJ. Evolution, classification and geographical distribution. In: Peters W and Killick-Kendrick R eds. The Leishmaniases: Biology and medicine, vol.1. London: Academic Press; 1987. p. 1-120.

Lainson R. Demographic changes and their influence on the epidemiology of the American leishmaniasis. In: Service MW ed. Demography and Vector-Borne Diseases. Boca Raton, FL: CRC Press; 1989. p. 85-106.

Lainson R, Shaw JJ, Silveira FT, Souza AAA, Braga R, Ishikawa EAY. The dermal leishmaniases of Brazil, with special reference to the Eco-epidemiology of the Disease in Amazonia. Mem Inst Oswaldo Cruz 1994; 89: 435-443. 
Leopoldo e Silva R, Corrêa FMA, Gomes AC, Yoshida ELA. Investigação epidemiológica sobre a leishmania tegumentar no município de Conchas, Estado de S. Paulo, Brasil. Rev Ciên Bioméd 1984; 5: 49-55.

Lewis DJ. Ward RD. Transmission and Vectors. In: Peters W and Killick-Kendrick R eds. The Leishmaniases biology and medicine. vol.1. London: Academic Press; 1987. p. $235-262$.

Lysenko AJ, Beljaev AE. Quantitative approches to epidemiology. In: Peters W and Killick-Kendrick $\mathrm{R}$ eds. The Leishmaniases biology and medicine. vol.1. London: Academic Press; 1987. p. 263-290.

Manly BFJ, Parr MJ. A new method of estimating population size, survivorship, and birth rate from capture-recapture data. Trans Soc British Entomol 1968; 18: 81-89.

Marcondes CB. A redescriptions of Lutzomyia (Nyssomyia) intermedia (Lutz \& Neiva, 1912), and resurrection of L. neivai (Pinto, 1926) (Diptera, Psychodidae, Plebotominae). Mem Inst Oswaldo Cruz 1996, 91:457-462

Marcondes CB. Morfometria e DNA mitocondrial de populaces sul americanas de Lutzomyia (Nyssomyia) intermedia (Lutz \& Neiva, 1912) (Diptera, Psychodidae, Plebotominae). Curitiba; 1997. (Tese de Doutorado - Universidade Federal do Paraná). 
Marcondes CB, Lazovei AL, Vilela JH. Distribuição geográfica de flebotomíneos do complexo Lutzomyia intermedia (Lutz \& Neiva, 1912) (Diptera, Psychodidae). Rev Soc Bras Med Trop 1998; 31(1): 51-58.

Mascarini LM, Casanova C, Cipolli EAR, Mayo RC. Caracterização do peıfil epidemiológico da Leishmaniose Tegumentar Americana (LTA) na Bacia do Rio Mogi-guaçu. Estado de São Paulo [resumo]. Rev Patol Trop 1995; 23 (2 Supl.): 336. [Apresentado no XIV Congresso Brasileiro de Parasitologia].

Mayo RC, Casanova C, Mascarini LM, Pignatti MG, Rangel O, Galati EAB, Wanderley DMV, Corrêa FMA. Flebotomineos (Diptera, Psychodidae) de área de transmissão de leismaniose tegumentar americana, no município de Itupeva, região sudeste do Estado de São Paulo, Brasil. Rev Soc Bras Med Trop 1998; 31(4): 339345.

Mayrink W, Williams P, Coelho MV, Dias M, Viana Martins A, Magalhães PA, Costa CA, Falcão AR, Mello MN, Falcão AL. Epidemiology of dermal leishmaniosis in the Rio Doce Valley, State of Minas Gerais, Brazil. Ann Trop Med Parasit 1979; 73: 123-37.

Milby MM. Reisen WK. Estimation of vectorial capacity: vector survivorship. Bull Soc Vector Ecol 1989; 14: 47-54. 
Montoya-Lerma J, Lane RP. Factors affecting host preference of Lutzomia evansi (Diptera: Psychodidae), a vector of visceral leishmaniasis in Colombia. Bull Entomol Research 1996; 86: 43-50.

Morrison AC, Ferro C. Morales A, Tesh RB, Wilson ML. Dispersal of the sand fly Lutzomyia longipalpis (Diptera: Psychodidae) at an endemic focus of visceral leishmaniasis in Colombia. J Med Entomol 1993; 30: 427-35.

Mutinga MJ, Kamau CC, Basimike M, Mutero CM, Kyai FM. Studies on the epidemiology of leishmaniasis in Kenya: flight range of phlebotomine sandflies in Marigat, Baringo District. East African Medical Journal 1992; 69: 9-13.

Natal D, Marucci D. Aparelho de sucção tipo aspirador para captura de mosquitos. Rev Saúde Pública 1984; 18: 418-420.

Nelson RL, Milby MM, Reeves WC, Fine PEM. Estimates of survival, population size, and emergence of Culex tarsalis at an isolated site. Ann Entomol Soc Amer 1978; 71: 801-808.

Pardo RH, Torres M, Morrison AC, Ferro C. Effect of fluorescent powder on Lutzomyia longipalpis (Diptera: Psychodidae) and a simple device for marking sand flies. J Am Mosq Control Assoc 1996; 12(2): 235-42. 
Passos VMA, Falcão AL, Marzochi MCA, Gontijo CMF, Dias EGO, Barbosa-Santos EGO, Guerra HL, Katz N. Epidemiological aspects of american cutaneous leishmaniasis in a periurban área of the metropolitan region of Belo Horizonte, Minas Gerais, Brazil. 1993 Mem Inst Oswaldo Cruz 1993; 88: 103-110.

Pessôa SB, Martins AV. Parasitologia Médica. 9 edição Guanabara-Koogan S.A; 1974.

Pinto MC, Campbell-Lendrum DH, Lozovei AL, Teodoro U, Davies CR. Phlebotomine sandfly responses to carbon dioxide and human odour in the field. Med Vet Entomol 2001, 15: 132-139.

Queiroz RG, Vasconcelos IAB, Vasconcelos AW, Pessoa FAC, Sousa RN, David JR. Cutaneous leishmaniasis in Ceara Satate in Northeastern Brazil: incrimination of Lutzomyia whitmani (Diptera: Psychodidae) as a vector of Leishmania braziliensis in Baturite municipality. Am J Trop Med Hyg 1994; 50: 693-8.

Quinnell RJ, Dye C, Shaw JJ. Host preferences of the phlebotomine sandfly Lutzomia longipalpis in Amazonian Brazil.Med Vet Entomol 1992; 6: 195-200.

Quinnell RJ, Dye. Correlates of the peridomestic abundance of Lutzomia longipalpis (Diptera: Psychodidae) in Amazonian Brazil.Med Vet Entomol 1994; 8: 219-24. 
Rangel EF. Souza NA, Wermelinger ED, Azevedo ACR, Barbosa AF. Infecção natural de Lutzomya intermedia Lutz \& Neiva, 1912, em área de leishmaniose tegumentar no Estado do Rio de Janeiro. Mem Inst Oswaldo Cruz 1984; 79: 395 396.

Rangel EF, Souza NA, Wermelinger ED, Barbosa AF. Estabelecimento de colônia, em laboratório, de Lutzomya intermedia Lutz \& Neiva, 1912 (Diptera, Psychodidae, Phlebotominae). Mem Inst Oswaldo Cruz 1985; 80(2): 219-26.

Rangel EF, Souza NA, Wermelinger ED, Azevedo ACR, Barbosa AF, Andrade CA. Flebótomos de Vargem Grande, foco de Leishmaniose Tegumentar no Estado do Rio de Janeiro. Mem Inst Oswaldo Cruz 1986; 81: 347-349.

Rangel EF, Souza NA, Wermelinger ED, Azevedo ACR, Barbosa AF, Andrade CA. Studies on sandfly fauna (Diptera: Psychodidae) in a loci of cutaneous Leishmaniases in Mesquita, Rio de Janeiro State, Brazil. Mem Inst Oswaldo Cruz 1990: 85(1): 3945.

Rangel EF, Barbosa AF, Andrade CA, Souza NA, Wermelinger ED. Development of Leishmania (Viannia) braziliensis viannia, 1991 in Lutzomia intermedia (Lutz \& Neiva, 1912) (Diptera: Psychodidae: Phlebotominae) under experimental conditions. Mem Inst Oswaldo Cruz 1992: 87(2): 235-38. 
Rangel EF, Lainson R. Souza AA, Ready PD, Azevedo CR. Variation between geographical populations of Lutzomyia (Nyssomia) whitmani (Antunes \& Coutinho, 1939) sensu lato (Diptera: Psychodidae: Phlebotominae) in Brazil. Mem Inst Oswaldo Cruz 1996; 91(1): 43-50.

Reisen WK. Estimation of vectorial capacity: introduction. Bull Soc Vector Ecol $1989 ; 14: 39-40$.

Reisen WK, Aslamkhan M. A release-recapture experiment with the malaria vector, Anopheles stephensi Liston, with observations on dispersal, survivorship, population size, gonotrophic rhythm and mating behaviour. Ann Trop Med Parasitol 1979; 73(3): 251-268.

Reisen WK, Mahmood F, Parveen T. Anopheles culicifacies Giles: a releaserecapture experiment with cohorts of known age with implications for malaria epidemiology and genetical control in Pakistan. Trans R S Trop Med Hyg 1980; 74: 307-317.

Reisen WK, Mahmood F, Azra K. Anopheles culicifacies Giles: adult ecological parameters measured in rural Punjab province, Pakistan using capture-mark-releaserecapture and dissection methods, with comparative observations on An. stephensi Liston and An. subpictus Grassi. Res Poul Ecol 1981; 23: 39-60. 
Reisen WK, Boreham PFL. Estimates of malaria vectorial capacity for Anopheles culicifacies and Anopheles stephensi in rrual Punjab Province, Pakistan. J Med Entomol 1982; 19(1): 98-103.

Reisen WK, Milby MM, Meyer RP, Pfuntner AR, Spoehel J, Hazelrigg JE, Webb Jr JP. Mark-release-recapture studies with Culex mosquitoes (Diptera: Culicidae) in Southern California. J Med Entomol 1991; 28: 357-371.

Reisen WK. Milby MM, Meyer RP. Population dynamics of adult Culex mosquitoes (Diptera: Culicidae) along the kern river, kern county, California, in 1990. J Med Entomol 1992; 29 (3): 531-543.

Reisen WK, Lothrop HD. Population ecology and dispersal of Culex tarsalis (Diptera: Culicidae) in the Coachella Valley of California. J Med Entomol 1995; 32(4): 490-502.

Rocha e Silva EO, Capinzaiki NA, Kuratomi CA, Guedes AC. A Leishmaniose Tegumentar Americana no Litoral Sul do Estado de São Paulo. Rev bras Malariol D Trop 1980; 32: 9-25.

Santos RLC. Medida da capacidade vetorial de Anopheles albitarsis e de Anopheles (Kerteszia) da região sudeste do Brasil. São Paulo; 2001. [Tese de Doutorado - Faculdade de Saúde Pública da USP]. 
Secretaria de Estado da Saúde-Centro de Vigilância Epidemiológica. Manual de Vigilância Epidemiológica - Leishmaniose Tegumentar Americana, Normas e Instruções. São Paulo 1995

Service MW. Mosquito Ecology. Field Sampling Methods. 2ed. Chapman \& Hall; 1993.

Shaw J.J, Lainson R. Leishmaniasis in Brazil: II. Observations on enzootic rodent leishmaniasis in the Lower Amazon Basin region - the feeding habits of the vector, Lutzomyia flaviscutellata in reference to man, rodents and other mammals. Trans Roy Soc Trop Med Hyg 1968; 62: 396-405.

Shaw JJ, Lainson R. Ecology and epidemiology: New World. In: Peters W, KillickKendrick R., eds. The leishmaniasis: Biology and Medicine. Vol. I. New York: Academic Press; 1987. p. 292-363.

Siqueira AF. Estudos sobre a reação de precipitina aplicada à identificação do sangue ingerido por triatomíneos. Rev Inst Med Trop 1960; 2: 41-53.

Southwood TRE. Ecological methods with particular reference to the study of insect populations. London: Chapman \& Hall; 1978. 
Takken W. Charlwood JD, Billingsley, PF, Gort G. Dispersal and survival of Anopheles funestus and A. gambie s.l. (Diptera: Culicidae) during the rainy season in southeast Tanzania. Bull Entomol Res 1998; 88: 561-566.

Taniguchi HH, Tolezano JE, Corrêa FMA, Moraes RHP, Veiga RM, Marassa AM. Epidemiologia da Leishmaniose Tegumentar Americana no Estado de São Paulo, Brasil. I- Composição da fauna flebotomínica no município de São Roque, região de Sorocaba. Rev Inst Adolfo Lutz 1991; 51: 23-30.

Tempelis $\mathrm{CH}$. Host-feeding patterns of mosquitoes with a review of advances in analysis of blood meals by serology. J Med Ent 1975; 11: 635-653.

Teodoro U, Rodrigues VLCC, Rocha e Silva EO. 1983. Casos de leismaniose tegumentar americana observados na região administrativa de Campinas, ao lado do rio Mogi-Guaçu, Estado de São Paulo, Brasil. [apresentado no XIX Congresso da Sociedade Brasileira de Medicina Tropical].

Teodoro U. Características ecológicas de flebotomíneos (Diptera, Psychodidae) em habitats antrópicos, município de Jussara, Paraná, Brasil. Curitiba; 1995. (Tese de Doutorado - Universidade Federal do Paraná).

Tesh RB, Chaniotis BN, Aronson M, Johnson KM. Natural host preferences of Panamanian phlebotomine sandflies as determined by precipitin test. Am J Trop Med Hyg 1971; 20: 150-156. 
Tesh RB, Chaniotis BN, Carrera BR, Johnson KM. Further studies on the natural host preferences of Panamanian phlebotomine sandflies. Am J Epidemiol 1972; 95: 8893.

Thatcher VE, Hertigi M. Field studies on the feeding habits and diurnal shelters of some Phlebotomus sandflies (Diptera: Psychodidae) in Panama. Ann Ent Soc Amer 1966; 59: 46-52.

Thatcher VE. Studies of phlebotomine sandflies using castor oil traps baited with Panamanian animals. J Med Ent 1968; 5: 293-297.

Tolezano JE, Marcoris SAG, Diniz JMP. Modificação na Epidemiologia da Leishmaniose Tegumentar no Vale do Ribeira, Estado de São Paulo, Brasil. Rev Inst Adolfo Lutz 1980; 40: 49-54.

Tolezano JE. Ecoepidemiological aspects of american cutaneous leishmaniasis in the State of São Paulo, Brazil. Mem Inst Oswaldo Cruz 1994; 89(3): 427-34.

Veloso HP; Rangel Filho ALR; Lima JCA. Classificação da vegetação brasileira adaptada a um sistema universal. Rio de Janeiro, IBGE, Departamento de Recursos naturais e Estudos Ambientais.

Vexenat JA, Barreto AC, Cuba CC. Marsden PD. Características epidemiológicas da leishmaniose tegumentar americana em uma região endêmica do Estado da Bahia. III - Fauna flebotomínica. Mem Inst Oswaldo Cruz 1986; 81: 293-301. 
Washino RK, Tempelis CH. Mosquito host bloodmeal identification: Methodology and data analysis. Ann Rev Entomol 1983; 28: 179-201.

Weitz B. Identification of blood meals of bloodsucking arthropods. Bull WId Hlth Org 1956; 15: 473-490.

Weitz B. Feeding habits of bloodsucking arthropods. Exp Parasitol 1960; 9: 63-82.

World Health Organization. Expert Committee on the control of the Leishmaniases.

Report. Geneva; 1990. (WHO - Technical Report Series, 793).

Young DG, Lawyer PG New World vectors of the leishmaniasis. Current Topics in Vector Research 1987; 4: 29-71.

Young DG, Duncan MA. Guide to identification and geographic distribution of Lutzomyia sand flies in Mexico, the West Indies, Central and South America (Diptera: Psychodidae). Mem Amer Ent Inst 1994; 54: 1-881. 